\title{
Access to the cis-Fused Stereoisomers of the Proline Analogues Containing an Octahydroindole Core
}

\author{
Francisco J. Sayago, ${ }^{[\mathrm{a}]}$ Pedro Laborda, ${ }^{[\mathrm{a}]}$ M. Isabel Calaza, ${ }^{[\mathrm{a}]}$ Ana I. Jiménez, ${ }^{[\mathrm{a}]}$ and Carlos \\ Cativiela*[a] $^{*[a}$
}

\author{
In Memory of Prof. José M. Concellón
}

\begin{abstract}
An overview of the synthetic methods developed to build all the cis-fused stereoisomers of octahydroindole-2-carboxylic acid (Oic) and its $\alpha$-methylated derivative $[(\alpha \mathrm{Me}) \mathrm{Oic}]$ in enantiomerically pure form is presented. Both asymmetric synthetic strategies (auxiliary- or substrate-controlled processes) and procedures based

on the resolution of racemic compounds (chemical, enzymatic, and chromatographic processes) are summarized. Special emphasis has been made on those strategies able to provide multigram quantities of enantiopure compounds, a prerequisite to make downstream biological applications feasible.
\end{abstract}

1. Introduction

2. Asymmetric synthesis

2.1. Auxiliary-controlled methods

2.2. Substrate-controlled methods

3. Resolution procedures

3.1. Chemical resolutions

3.2. Enzymatic resolutions

3.3. Chromatographic resolutions

4. Concluding remarks

5. Abbreviations and acronyms

[a] Departamento de Química Orgánica, Instituto de Ciencia de Materiales de Aragón, Universidad de Zaragoza-CSIC, 50009

Zaragoza, Spain

Fax: +34 976761210

E-mail: cativiela@unizar.es

\section{Introduction}

Peptides influence numerous biological processes (acting as hormones, enzyme inhibitors, neurotransmitters, antibiotics...) that affect vital physiological functions and, therefore, constitute very valuable leads for drug design. ${ }^{[1]}$ Moreover, the discovery of novel peptides, other than naturally occurring ones, is increasing because it is being simplified through the use of recombinant display technologies (phage, DNA/RNA....). ${ }^{[2]}$ One reason for this expansion is that peptide-based drugs have the key advantage of diminishing problems related with toxicology and safety, which are two of the main causes of failure when developing drugs of nonpeptidic nature. However, the therapeutic application of bioactive peptides is often limited by their low oral bioavailability and poor distribution as well as by the lack of specificity for a particular receptor. $^{[1,3]}$

In order to overcome such limitations, the pharmacokinetic profiles of peptides have been modified mostly through chemical optimization strategies along with new routes of administration. In fact, the intense investigation made in both fields has led to more than sixty synthetic peptides currently available as drugs on several areas of the pharmaceutical market. ${ }^{[3 a]}$
In this context, the rational modification of the intrinsic physicochemical properties of peptides through the incorporation of non-coded amino acids is one of the chemical strategies of active investigation. This is due to the versatility of unnatural amino acid residues, which can be purposely conceived to improve peptide stability towards proteases, to enhance the ability to cross physiological membranes or to reduce conformational flexibility, and these changes often result in enhanced potency and specificity. Furthermore, the incorporation of non-proteinogenic residues into peptides assures chemical diversity, which is a key issue for generating patentable drugs.

Among non-coded amino acids, proline analogues are of particular interest given the key role of proline in nucleating the secondary structure, and hence the function, of peptides. ${ }^{[4]}$ In particular, octahydroindole-2-carboxylic acid (Oic) and its $\alpha$ methylated counterpart $[(\alpha \mathrm{Me}) \mathrm{Oic}]$ hold considerable interest due to their well-suited structural features (Figure 1). Their bicyclic structure introduces certain backbone rigidity when incorporated into peptides, similar to that induced by proline. This structural restriction may contribute not only to improve the resistance to degrading enzymes but also to enhance target binding and selectivity properties through the stabilization of specific secondary structural motifs. These properties may be particularly enhanced in the case of the $\alpha$-methylated derivative due to the tetrasubstituted character of the $\alpha$ carbon. ${ }^{[5]}$ At the same time, both Oic and $(\alpha \mathrm{Me})$ Oic are proline analogues endowed with greater lipophilicity and hydrophobic size, which may generate peptides exhibiting increased bioavailability or providing improved binding interactions at the receptor active site.<smiles>O=C(O)C1CC2CCCCC2N1</smiles><smiles>[N+]=C1CC2=C(CCCC2)N1</smiles>

Oic

$(\alpha \mathrm{Me})$ Oic

Figure 1. General structure of octahydroindole-2-carboxylic acid (Oic) and its $\alpha$-methyl derivative [( $\alpha \mathrm{Me}) \mathrm{Oic}]$. The position of the chiral carbons is indicated.

In particular, Oic has already contributed to improve the enzymatic stability and potency of several Bradykinin $\mathrm{B}_{2}$ 
antagonists such as Icatibant (Figure 2), which has recently received European approval for the treatment of hereditary angioedema. ${ }^{[6]}$ Moreover, Oic is a part of the suberimidyl dimer CU-201 (Figure 2), currently under development as a possible drug for lung cancer. ${ }^{[7]}$ Oic is also present in the pentapeptide FM19 (Figure 2), which is an orally active investigational drug able to inhibit platelet aggregation and is therefore of use in the management of acute coronary syndrome. ${ }^{[8]}$ The ability of Oic to induce $\beta$-turn motifs, which is operational in Icatibant, ${ }^{[6 \mathrm{~d}]}$ has also been used for the de novo design of selective antibiotic peptides. ${ }^{[9]}$ Besides, the sterically constrained structure of this bicyclic proline analogue has proven useful to determine the physiological role of certain melanocortin receptors (hMCR) through the design of potent and selective agonists towards the receptor subtype 5 as, for example, compound OBP-MTII (Figure 2). ${ }^{[10]}$

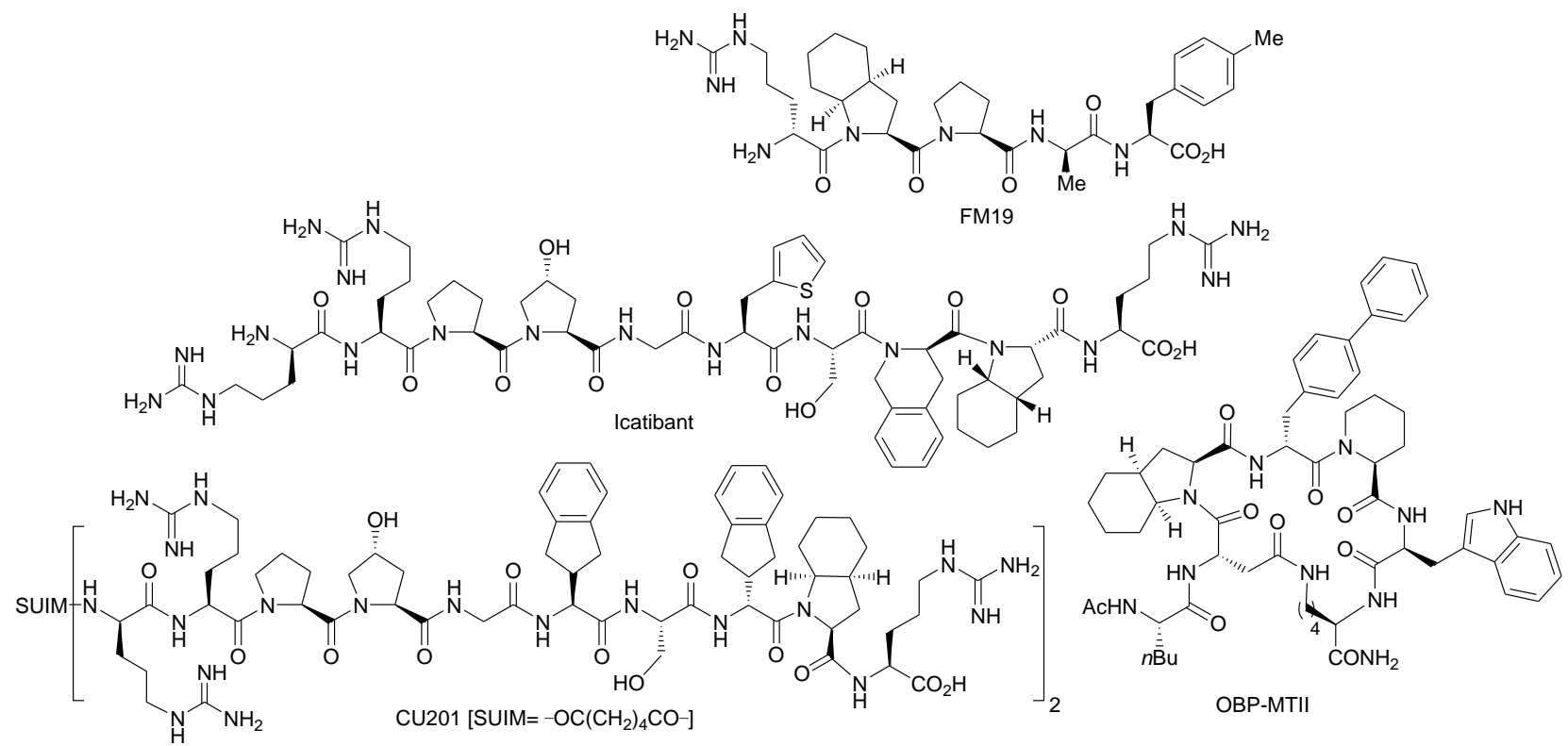

Figure 2. Examples of modified peptides containing Oic that exhibit pharmacologically relevant properties. 
In the field of peptidomimetic design, Oic has found application in the elaboration of medicinally relevant compounds such as perindoprii $^{[11]}$ (Figure 3), an angiotensin-converting enzyme (ACE) inhibitor which is one of the top antihypertensive drugs on the market. Oic is also a part of a series of potent prolyl oligopeptidase (POP) inhibitors. Among them, S17092 ${ }^{[12]}$ (Figure 3) is under investigation for the treatment of neurodegenerative diseases like Alzheimer's and Parkinson's. Moreover, Oic is present in several potent and selective human leukocyte elastase (HLE) inhibitors that may provide a powerful in vivo protection against pulmonary tissue destruction. ${ }^{[13]}$

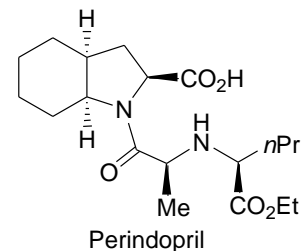<smiles>CC(C)c1cc(CC(=O)NS(=O)(=O)c2ccc(C(=O)N3[C@@H](C(=O)N[C@H](C(=O)O)C(F)(F)F)C[C@@H]4CCCC[C@H]43)cc2)cc(C(C)(C)C)c1O</smiles>

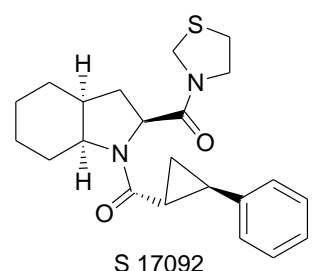

HLE inhibitor

Figure 3. Some Oic-containing peptidomimetics with pharmacologically relevant properties.

Besides, the octahydroindole-2-carboxylic acid scaffold containing additional functionalities is found in the structure of aeruginosins (Figure 4), a family of bioactive naturally-occurring alkaloids that act as thrombin, trypsin, and factor VIIa inhibitors. ${ }^{[14]}$ Even if most of the aeruginosins discovered contain hydroxy groups at the azabicyclic unit, some unnatural surrogates incorporating unsubstituted Oic have been synthesized and found to exhibit increased activity against thrombin (Figure 4). ${ }^{[14 c]}$
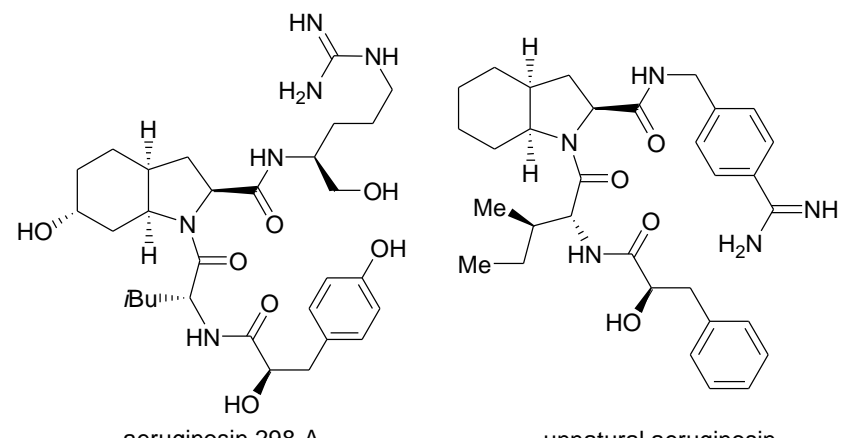

Figure 4. Example of a naturally-occurring aeruginosin and a synthetic surrogate containing unsubstituted Oic.

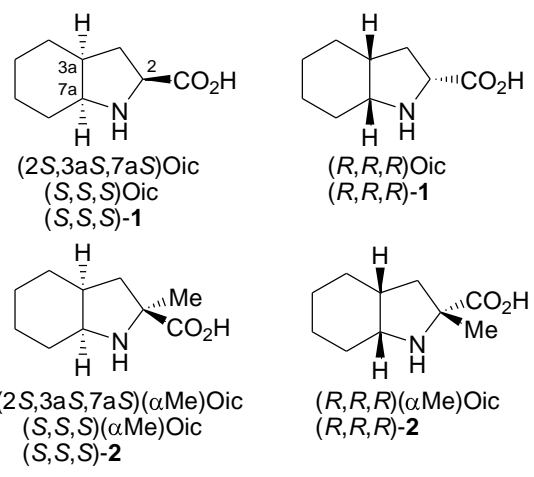

Additionally, compounds including an $\alpha$-methyl group anchored at the $\alpha$ carbon of the perhydroindole-2-carboxylic acid core (Figure 5) have been reported to exhibit potential applications for treating osteoarthritis. ${ }^{[15]}$<smiles>CO[C@H]1C[C@@H]2CCCC[C@H]2N1C</smiles>

Figure 5. Example of a pharmacologically active ( $\alpha$ Me)Oic derivative.

Besides the attractiveness of Oic derivatives for drug generation outlined before, additional interest on these compounds stems from their potential utility to carry out chemical transformations with the induction of chirality. In fact, some Oic derivatives have already been used as chiral ligands or catalysts (Figure 6). ${ }^{[16]}$<smiles>COC(c1ccccc1)(c1ccccc1)C1CC2CCCC[C@H]2N1</smiles><smiles>O=C(NP)C1CC2CCCC[C@H]2N1</smiles><smiles>O=C(N[C@H](c1ccccc1)[C@@H](NC(=O)[C@@H]1C[C@H]2CCCC[C@H]2N1)c1ccccc1)[C@H]1[CH]CCCC1</smiles>

Figure 6. Some organocatalysts and chiral ligands derived from Oic.

It should be noted that all the applications mentioned above (Figures 2-6) concern compounds containing the same Oic stereoisomer, namely that exhibiting a $(2 S, 3 \mathrm{a} S, 7 \mathrm{a} S)$ stereochemistry [hereafter denoted ${ }^{[17]}$ as $(S, S, S)$ Oic or $(S, S, S)-\mathbf{1}$, Figure 7]. Actually, this is the only Oic stereoisomer whose applications in different fields have been thoroughly explored and this is due to the easy accessibility to this particular template in enantiomerically pure form. It is, in fact, the lack of effective synthetic methodologies for ready accessibility to the other Oic stereoisomers that has limited their applications to date. The same holds true for all $(\alpha \mathrm{Me})$ Oic stereoisomers.

In recent years, the relevant properties exhibited by compounds containing $(S, S, S)$ Oic has stimulated the search for synthetic methodologies leading to other Oic stereoisomers, particularly those characterized by a cis-configuration at the ring junction, as well as to their $\alpha$-methylated counterparts. The present paper intends to illustrate the progress of the synthetic methods developed for the construction of all cis-fused Oic and ( $\alpha \mathrm{Me}) \mathrm{Oic}$ stereoisomers (Figure 7$)^{[17]}$ in enantiomerically pure form either by asymmetric synthesis or by combining a racemic synthesis with a resolution procedure.<smiles>O=C(O)C1CC2CCCCC2NC1S(=O)(=O)O</smiles><smiles>O=C(O)C1CC2CCCCC23NC1[Pb]3[OH+]</smiles><smiles>O=[N+]([O-])C1CC2CCCC[C@H]2N1</smiles>

$(R, S, S)(\alpha \mathrm{Me})$ Oic $(R, S, S)-2$

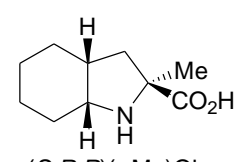

$(S, R, R)(\alpha \mathrm{Me})$ Oic $(S, R, R)-2$

Figure 7. Structure of Oic and ( $\alpha \mathrm{Me})$ Oic stereoisomers with a cis-fused bicyclic skeleton. 
Various synthetic strategies have been devised for the preparation of the cis-fused stereoisomers of Oic. The most effective procedures involve the hydrogenation of a double bond connecting the bridgehead carbons of appropriate precursors such as the indole ${ }^{[18]}$ indoline ${ }^{[19,20]}$ or bicyclic enamine ${ }^{[21]}$ derivatives depicted in Figure 8 (type A substrates). The hydrogenation process ensures the cis relative disposition of the hydrogen atoms at the ring junction, and the construction of the cis-fused octahydroindole-2-carboxylic acid system is therefore accomplished in a straightforward manner.

Alternatively, a number of strategies make use of starting materials that already exhibit a cis relative disposition of the protons bonded to the carbon atoms involved in the fusion (type B substrates, Figure 8), but require further modifications such as ring closure $^{[22]}$ or contraction ${ }^{[23]}$ or the incorporation of the carboxylic acid moiety at the $\alpha$ carbon. ${ }^{[23,24]}$

In addition to the aforementioned routes, the construction of the cis fusion has been achieved through an intramolecular 5-exo-trig radical cyclization procedure (substrate C, Figure 8). ${ }^{[25]}$

A<smiles>[R]OC(=O)[C@H]1Cc2ccccc2N1</smiles>

B<smiles>[R]OC(=O)[C@@H]1C[C@@H](CC=C)[C@@H]([R])N1</smiles><smiles>[R]C1CCCC[C@@H]1CCN</smiles><smiles>O=C1N[C@H]2CCCC[C@H]2N1</smiles>

$n=1,2$

C<smiles>[R]OC(=O)[C@H](CC(=O)O[Na])NC1C=CCCC1</smiles>

Figure 8. Different types of precursors used for the synthesis of the cisfused stereoisomers of Oic and $(\alpha \mathrm{Me})$ Oic.

\section{Asymmetric procedures}

Nearly all the precursors previously disclosed have been used for the preparation of enantiopure cis-fused Oic stereoisomers. Most often, the synthetic strategies involve stereoselective transformations on chiral precursors but also the use of a prochiral synthon in combination with a chiral auxiliary has been reported.

\subsection{Auxiliary-controlled methods}

Dubuffet et al have demonstrated ${ }^{[24]}$ the utility of $(S)$ phenylglycinol as a chiral auxiliary for the preparation of the cisfused bicyclic pyrrolidinone 8, which was further elaborated to generate enantiomerically pure $(S, S, S)-\mathbf{1}$ (Scheme 1). Thus, the condensation of the keto-acid 3 and $(S)$-phenylglycinol (4) in toluene with azeotropic removal of water gave the tricyclic lactam 5. The auxiliary induced the simultaneous establishment of the two contiguous stereogenic centers with a complete stereochemical control, and provided lactam $\mathbf{5}$ as a single stereoisomer. The stereoselective replacement of the oxazolidine $\mathrm{C}-\mathrm{O}$ bond with a hydrogen atom was achieved by treatment of $\mathbf{5}$ with triethylsilane in the presence of boron trifluoride etherate. The Lewis acid presumably coordinates with the oxazolidine oxygen to promote the formation of an iminium ion and the departing oxygen directs the delivery of hydride with retention of configuration. The cleavage of the chiral auxiliary was then achieved by treatment of 6 with thionyl chloride, followed by hydrolysis of the resulting enamide (7) under acidic conditions. Subsequent standard synthetic transformations on the lactam moiety of pyrrolidinone $\mathbf{8}$ gave rise to $\mathbf{1 0}$ that was further hydrogenated to afford $(S, S, S)-\mathbf{1}$ in $99 \%$ enantiomeric excess. Unfortunately, details were not provided in this patent concerning the stereoselectivity of the hydrogenation reaction. Presumably, the steric hindrance produced by the cyclohexane moiety in $\mathbf{1 0}$ plays a crucial role in stereodirecting the hydrogenation reaction to give $(S, S, S)$-1 rather than the isomer exhibiting an $(R, S, S)$ stereochemistry. Moreover, no conclusion can be drawn regarding the effectiveness of the synthetic method due to the lack of information on the yield of each individual step.
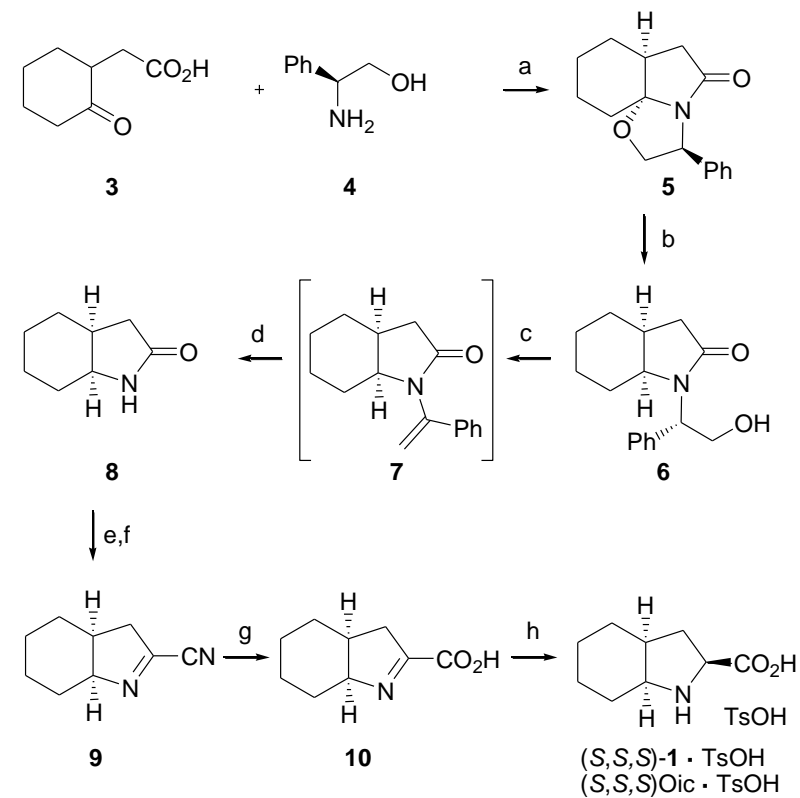

Scheme 1 . Synthesis of enantiomerically pure $(S, S, S)$ Oic by condensation of (2-oxocyclohexyl)acetic acid and $(S)$-phenylglycinol, according to ref. 24. Reagents and conditions: a) Toluene, reflux, Dean-Stark; b) $\mathrm{Et}_{3} \mathrm{SiH}$, $\mathrm{BF}_{3} \cdot \mathrm{OEt}_{2}, \mathrm{CH}_{2} \mathrm{Cl}_{2}$, reflux; c) $\mathrm{SOCl}_{2}, \mathrm{CH}_{2} \mathrm{Cl}_{2}$, reflux; d) aq. $\mathrm{H}_{2} \mathrm{SO}_{4} 5 \mathrm{M}$; e) $\mathrm{Tf}_{2} \mathrm{O}, i \mathrm{Pr}_{2} \mathrm{EtN}, \mathrm{CH}_{2} \mathrm{Cl}_{2}$, r.t.; f) LiCN, 12 -crown-4 ether, THF, r.t.; g) aq $\mathrm{HCl} 20 \%$, reflux; h) $\mathrm{H}_{2}$ (5 bar), $10 \% \mathrm{Pd} / \mathrm{C}, \mathrm{AcOH}$, r.t.; then $\mathrm{TsOH}, 30{ }^{\circ} \mathrm{C}$. Data on the reaction yields are not provided by the authors.

\subsection{Substrate-controlled methods}

Alternatively, Dubuffet et al reported ${ }^{[21 b]}$ the preparation of enantiomerically pure $(S, S, S)-\mathbf{1}$ by employing enantiopure $N$-Boc$\beta$-iodo-L-alanine benzyl ester (13) as the source of chirality (Scheme 2). This compound, which is easily derived from L-serine in a four-stage sequence, ${ }^{[26]}$ was reacted with the enamine (12) derived from cyclohexanone and pyrrolidine to give 14. Removal of the $\mathrm{N}$-Boc protecting group provided an amino ester which cyclized to 15 upon heating under acidic conditions. Subsequent catalytic hydrogenation ensured the cis relative disposition of the hydrogen atoms at the ring junction and cleaved the benzyl ester, thus yielding $(S, S, S)-\mathbf{1}$ in $87 \%$ yield and $99 \%$ enantiomeric excess. Also in this case, details were not given by the authors concerning the stereoselectivity of the hydrogenation step that could presumably render a small percentage of epimeric $(S, R, R)-\mathbf{1}$ together with the main product. Probably, the process proceeds in a quite diastereoselective fashion towards $(S, S, S)-\mathbf{1}$ due to the stereodirecting effect produced by the carboxylic acid moiety in $\mathbf{1 5}$. 


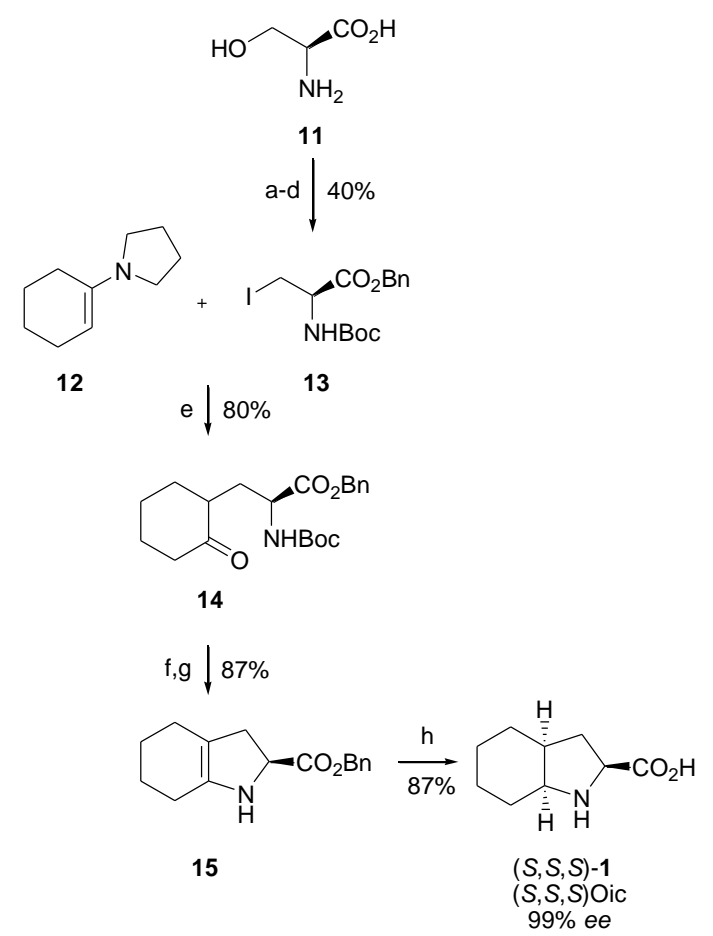

Scheme 2. Synthesis of enantiomerically pure $(S, S, S)$ Oic from an L-alanine derivative, according to ref. 21b. Reagents and conditions: a) $\mathrm{PhSO}_{3} \mathrm{H}$, $\mathrm{BnOH}, \mathrm{CCl}_{4}$, reflux; b) $\mathrm{Boc}_{2} \mathrm{O}$, aq. $\mathrm{NaOH}$, THF, r.t.; c) TsCl, $\mathrm{Py},-10{ }^{\circ} \mathrm{C}$; d) $\mathrm{NaI}$, acetone, r.t.; e) $\mathrm{CH}_{3} \mathrm{CN}$, reflux; f) TFA, $\mathrm{CH}_{2} \mathrm{Cl}_{2}$, r.t.; g) $\mathrm{TsOH}$, toluene, reflux, Dean-Stark; h) $\mathrm{H}_{2}$ (5 bar), $10 \% \mathrm{Pt} / \mathrm{C}, \mathrm{AcOH}$, r.t.

The preparation of $(S, S, S)-\mathbf{1}$ has also been achieved through the cyclization of a radical carbon generated on the side chain of an Laspartic acid derivative (Scheme 3). ${ }^{[25]}$ The photochemical treatment of the $\mathrm{N}$-hydroxy-2-thiopyridone ester $\mathbf{1 7}$ produced a radical that underwent cyclization in moderate yield to provide a separable mixture of the $(S, R, R)$ and $(S, S, S)$ diastereoisomers, from which a derivative of $(S, S, S)$ Oic could be isolated after several transformations. However, no details were provided by the authors concerning the diastereoisomeric ratio attained upon the cyclization, the procedure for the isolation of 18a or the effectiveness of the subsequent transformations carried out on this compound. All these factors render the synthetic procedure not very convenient for the preparation of $(S, S, S)-\mathbf{1}$. Moreover, the protecting groups in $\mathbf{1 9}$ seem not to be very appropriate for undertaking further transformations, since they need to be eliminated under basic or acidic conditions that could affect the amino acid enantiomeric purity.

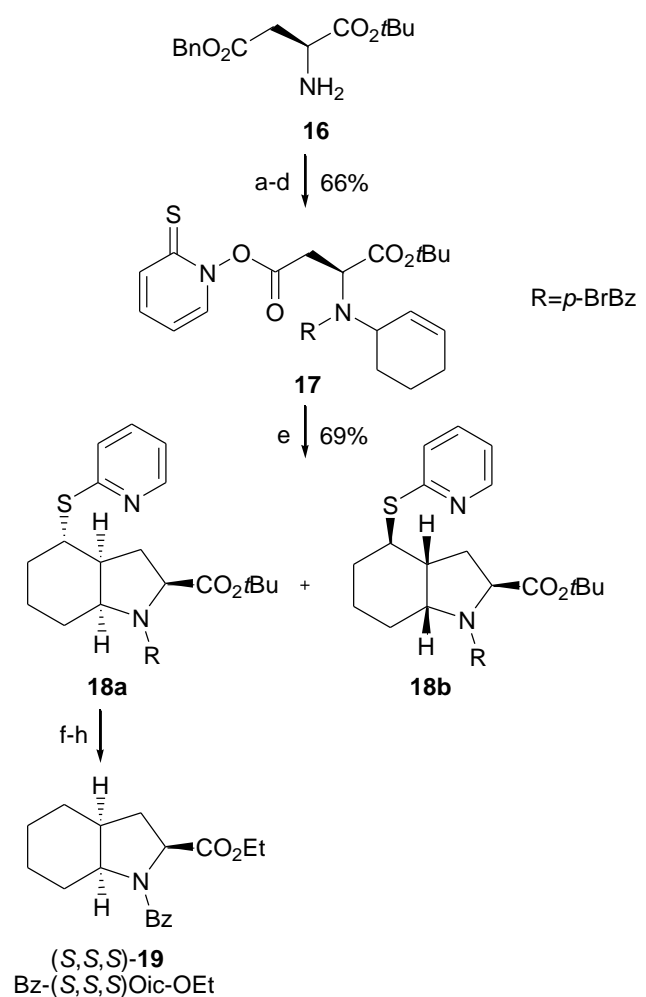

Scheme 3. Synthesis of an $(S, S, S)$ Oic derivative in enantiomerically pure form starting from an L-aspartic acid derivative, according to ref. 25. Reagents and conditions: a) 3-Bromocyclohex-1-ene, $\mathrm{K}_{2} \mathrm{CO}_{3}, \mathrm{CH}_{3} \mathrm{CN}$, r.t.; b) $p-\mathrm{BrC}_{6} \mathrm{H}_{4} \mathrm{COCl}, \mathrm{K}_{2} \mathrm{CO}_{3}$, acetone, r.t.; c) $2 \mathrm{~N} \mathrm{NaOH}$, DMF, r.t.; d) $i$ BuOCOCl, $N$-methylmorpholine, $N$-hydroxy-2-thiopyridone, $\mathrm{Et}_{3} \mathrm{~N}$, THF, $15{ }^{\circ} \mathrm{C}$; e) THF, hv, r.t.; f) Ni Raney, EtOH, r.t.; g) TFA, r.t.; h) EtBr, $\mathrm{NaHCO}_{3}, \mathrm{DMF}$. The procedure for the isolation of 18a and the yields of the subsequent steps are not provided by the authors.

The formation of the octahydroindole system has also been attained by ring-closing metathesis of a suitable diallylated proline derivative (Scheme 4). ${ }^{[22]}$ The starting L-glutamic acid derivative $\mathbf{2 0}$ was converted into $\mathbf{2 1}$ following a four-step synthetic pathway that emcopased an almost complete diastereoselective allylation of the Li-enolate of $\mathbf{2 0}$, deprotection of the amino function, thermal cyclization and reprotection of the lactam. Next, a selective reduction of the lactam $\mathbf{2 1}$ to the hemiaminal 22, followed by an acid-catalyzed allylation reaction provided a 25:75 syn/anti mixture of the diallylated products 23. Subsequent ring-closing metathesis of the isolated syn stereoisomer and hydrogenation of the resulting bicyclic compound provided the $N$-Boc protected methyl ester derivative of $(S, S, S)$ Oic. 


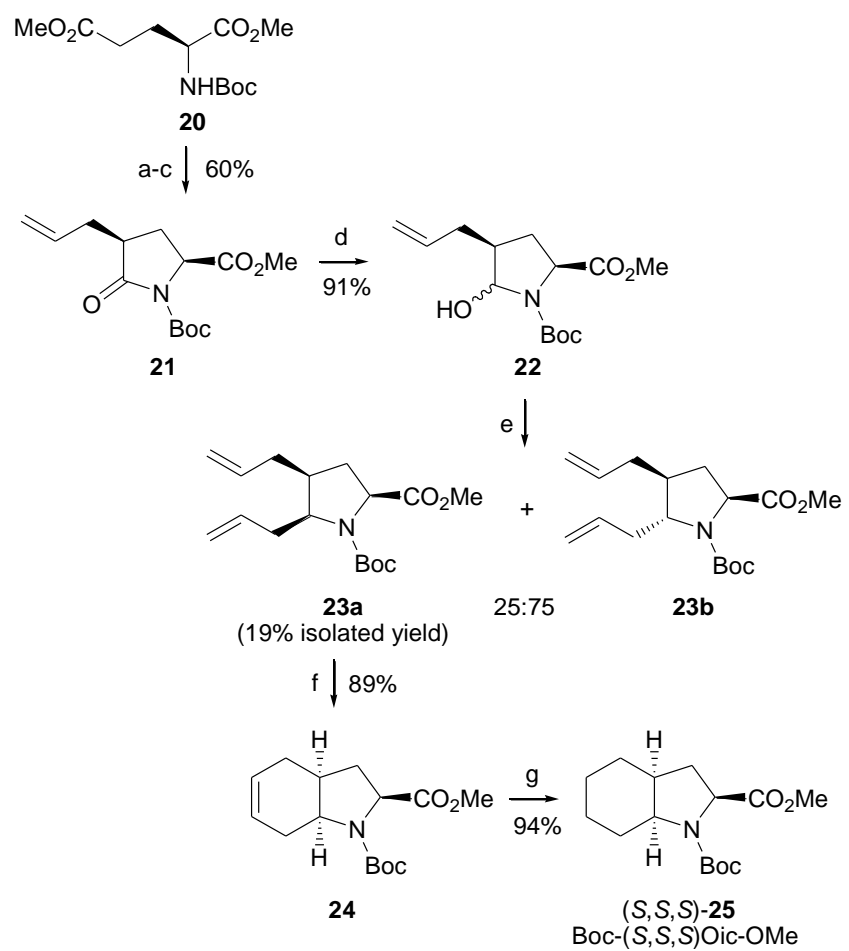

Scheme 4. Synthesis of an $(S, S, S)$ Oic derivative in enantiomerically pure form by ring-closing metathesis, according to ref. 22a. Reagents and conditions: a) HMDS, $n \mathrm{BuLi}$, allyl bromide, THF, $-78{ }^{\circ} \mathrm{C}$; b) 1 .TFA, $\mathrm{CH}_{2} \mathrm{Cl}_{2}, 0{ }^{\circ} \mathrm{C} ; 2$. Toluene, reflux; c) $\mathrm{Boc}_{2} \mathrm{O}$, DMAP, THF, r.t.; d) $\mathrm{LiEt}_{3} \mathrm{BH}$, THF, $-78{ }^{\circ} \mathrm{C}$; e) Allyltributylstannane, TBDMSOTf, $\mathrm{CH}_{2} \mathrm{Cl}_{2},-78{ }^{\circ} \mathrm{C}$; pure 23a was isolated by column chromatography; f) Grubbs catalyst, $\mathrm{CH}_{2} \mathrm{Cl}_{2}$, r.t.; g) $\mathrm{H}_{2}(2$ bar), $5 \% \mathrm{Pd} / \mathrm{C}, \mathrm{EtOH}$, r.t.

The introduction of the allyl group at the C5 position of hemiaminal 22 (Scheme 4) in such a low selectivity towards the syn stereoisomer renders this strategy not practical for the multigram preparation of $(S, S, S)$-1. However, Hanessian et al have recently described ${ }^{[22 b]}$ an improved syn-allylation reaction via related $N$-acyl iminium ion chemistry (Scheme 5). After an extensive optimization of the solvent, Lewis acid and protecting groups used, allylation of aminal $\mathbf{2 6}$ occurred with an 85:15 syn/anti selectivity, when performed in toluene with allyltributylstannane in the presence of boron trifluoride etherate. The major isomer (27a), which was easily separated by chromatography, underwent olefin methathesis to provide the corresponding carbocyclization product in excellent yield. ${ }^{[22 \mathrm{~b}]}$ Therefore, the overall synthetic strategy depicted in Scheme 4 could be efficiently applied to the preparation of $(S, S, S)-\mathbf{1}$ if aminal 26 (Scheme 5) would be employed as the substrate for the key synallylation step.

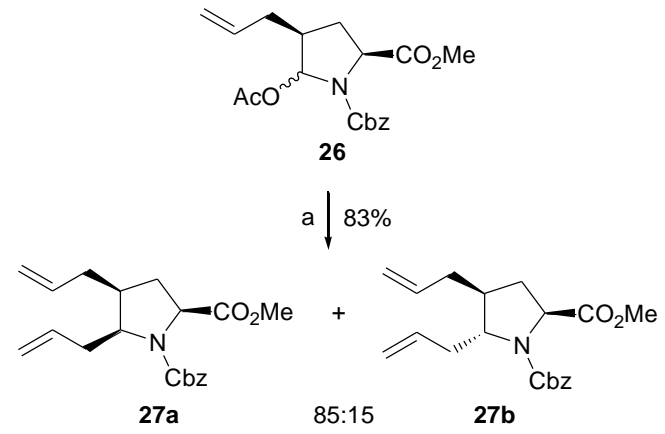

Scheme 5. Improved synthesis of a syn-diallylated compound that can serve as a precursor for $(S, S, S)$ Oic. Reagents and conditions: a) Allyltributylstannane, $\mathrm{BF}_{3} \cdot \mathrm{OEt}_{2}$, toluene, $-78^{\circ} \mathrm{C}$.
Among all the strategies reported for the preparation of enantiopure $(S, S, S)$-1 where the overall stereochemistry is directly influenced by an existing chiral center in the starting material, the most simple one involves the hydrogenation of $(S)$-indoline-2carboxylic acid, $(S)$-28. This is because the hydrogenation of this bicyclic precursor ensures the required cis relative disposition of the bridgehead atoms of the octahydroindole system in a single step.

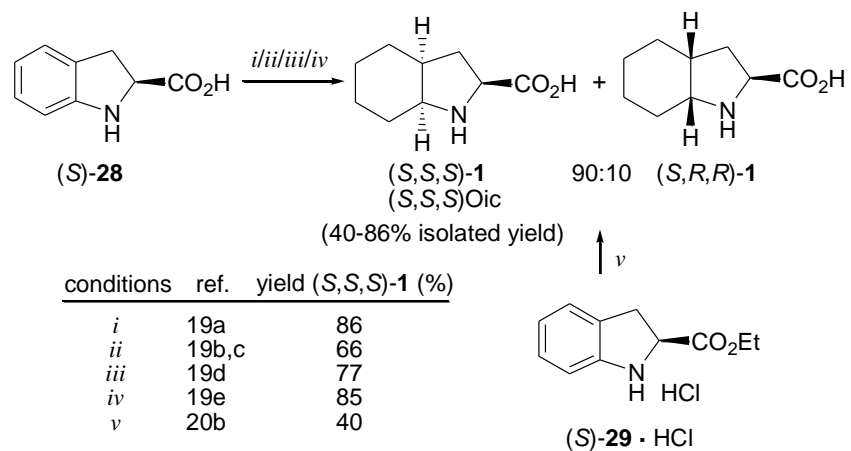

Scheme 6. Synthesis of enantiomerically pure $(S, S, S)$ Oic by hydrogenation of $(S)$-indoline-2-carboxylic acid or its ethyl ester derivative, according to ref. 19,20. Reagents and conditions: i) $\mathrm{H}_{2}(30 \mathrm{bar}), 5 \% \mathrm{Rh}, \mathrm{MeOH}, 60{ }^{\circ} \mathrm{C}$; recrystallization from dioxane $/ \mathrm{H}_{2} \mathrm{O}$; ii) $\mathrm{H}_{2}(50 \mathrm{bar}), 10 \% \mathrm{Pd} / \mathrm{C}, \mathrm{AcOH}, 50$ ${ }^{\circ} \mathrm{C}$; recrystallization from $\mathrm{Et}_{2} \mathrm{O}$; iii) $\mathrm{H}_{2}$ (12 bar), $5 \% \mathrm{Rh} / \mathrm{Al}_{2} \mathrm{O}_{3}, \mathrm{NaOH}, \mathrm{H}_{2} \mathrm{O}$, $50{ }^{\circ} \mathrm{C}$; recrystallization from $\mathrm{MeOH}$; iv) $\mathrm{H}_{2}, \mathrm{PtO}_{2}, \mathrm{AcOH}, 60{ }^{\circ} \mathrm{C}$, recrystallization from $\mathrm{EtOH} ; v) \mathrm{H}_{2}(50 \mathrm{bar}), 7.5 \% \mathrm{Pd} / \mathrm{C}, \mathrm{EtOH}, 60{ }^{\circ} \mathrm{C}$; then aq. $\mathrm{NaOH} 30 \%, 30^{\circ} \mathrm{C}$; recrystallization from $\mathrm{THF} / \mathrm{H}_{2} \mathrm{O}$.

Several catalytic systems and reaction conditions have been reported to date for this transformation (Scheme 6). ${ }^{[19]}$ Vincent et al were the first to describe that the hydrogenation of $(S)$-28 provides $(S, S, S)-\mathbf{1}$ in good yields when performed under pressure using rhodium ${ }^{[19 a]}$ or palladium/carbon ${ }^{[19 b, c]}$ as a catalyst (Scheme 6 , hydrogenation conditions $i$ and $i$ ). Presumably, the hydrogenation is highly selective in both cases, albeit the diastereoisomeric ratio has been stated by the authors only for the palladium-catalyzed reaction, which afforded a 90:10 mixture of $(S, S, S)-\mathbf{1}$ and $(S, R, R)$ 1. ${ }^{[19 \mathrm{c}]}$ On this basis, the low isolated yield of $(S, S, S)-\mathbf{1}(66 \%)$ might be attributed to an inefficient purification, carried out by recrystallization from diethyl ether. After that, a rhodium-catalyzed hydrogenation of $(S)$-28 at lower pressure of hydrogen (12 instead of 30 or 50 bar) and under basic reaction conditions was disclosed in a patent (Scheme 6, hydrogenation conditions iii), although the stereoselectivity was not mentioned. ${ }^{[19 \mathrm{~d}]}$ More recently, we have shown that the use of platinum oxide as a catalyst allows the hydrogenation of $(S)-\mathbf{2 8}$ to proceed at atmospheric pressure (Scheme 6, hydrogenation conditions $i v$ ) and this means a very practical advantage for a multigram scale production. ${ }^{[19 e]}$ Under these catalytic conditions, the carboxyl group in $(S)-\mathbf{2 8}$ was quite effective in orienting the approach of hydrogen and also afforded a 90:10 mixture of epimers, from which $(S, S, S)$-1 was isolated in $85 \%$ yield by recrystallization from ethanol. Additionally, the palladium-catalyzed hydrogenation of the ethyl ester derivative $(S)$ 29 has been described in a patent (Scheme 6, hydrogenation conditions $v$ ). ${ }^{[20 b]}$ Although the stereoselectivity of the process is not mentioned, the catalytic reduction of $(S)$-29 under pressure of hydrogen, followed by aqueous hydrolysis and recrystallization, is claimed to afford $(S, S, S)-\mathbf{1}$ in $40 \%$ overall yield.

The stereoselectivity reported ${ }^{[19 c, e]}$ for the hydrogenation of $(S)$ 28 under different conditions (Scheme 6) suggests that the hydrogenation of compounds $\mathbf{1 0}$ and $\mathbf{1 5}$ depicted in Schemes 1 and 2 , respectively, might occur in a highly selective fashion although data on the selectivity observed were not provided. ${ }^{[21 b, 24]}$ 
All the synthetic routes described so far addressed the preparation of the $(S, S, S)$ Oic stereoisomer. Obviously, they could be applied to the synthesis of enantiomeric $(R, R, R)$ Oic provided that starting materials with the opposite absolute configuration are employed.

In contrast, just a single methodology has been described for the preparation of $(R, S, S)$ Oic in enantiomerically pure form. It involves an epimerization reaction at the $\alpha$ position of enantiopure $(S, S, S)$ 1. ${ }^{[19 c, e]}$ Probably, this is the most simple approach to access $(R, S, S)$ Oic because any other retrosynthetic disconnection would require the use of more complex starting materials. Specifically, Vincent $e t a l^{[19 c]}$ reported the epimerization of enantiopure $(S, S, S)$ 1 by treatment with salicylaldehyde for 1.5 hours under acidic conditions to afford a 50:50 mixture of $(S, S, S)-\mathbf{1}$ and $(R, S, S)-\mathbf{1}$ (Scheme 7). The desired $(R, S, S)$ stereoisomer was isolated from the mixture after consecutive preferential crystallizations, thus making the synthesis very laborious and the global yield quite low (30\%).

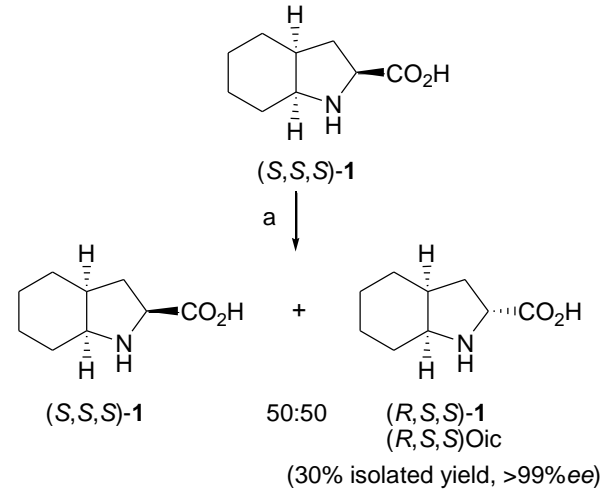

Scheme 7. Synthesis of enantiomerically pure $(R, S, S)$ Oic according to ref. 19c. Reagents and conditions: a) Salicylaldehyde, $\mathrm{AcOH}$, reflux, $1.5 \mathrm{~h}$; crystallization from EtOH to eliminate $(S, S, S)-\mathbf{1}$; recrystallizations of $(R, S, S)-\mathbf{1}$ from EtOAc and EtOH/EtOAc.

On this basis, we have reported an optimized method for the preparation of $(R, S, S)-\mathbf{1}$ (Scheme 8$),{ }^{[19 \mathrm{e}]}$ which combined an improved epimerization of $(S, S, S)-\mathbf{1}$ with a more competitive procedure for the separation of epimers, other than preferential crystallizations. Enantiomerically pure $(S, S, S)-\mathbf{1}$ was submitted to the aforementioned acidic epimerization conditions under a prolonged reaction time ( 24 hours), and this led to a considerable enrichment of the desired epimer in the diastereoisomeric mixture, with the final $(S, S, S)-\mathbf{1} /(R, S, S)-\mathbf{1}$ ratio being 23:77. Next, the mixture was submitted to condensation with trichloroacetaldehyde, which served as a tool for discrimination between the epimers. Thus, $(R, S, S)-\mathbf{1}$ provided the tricyclic oxazolidinone $(S, S, S, R)-\mathbf{3 0}$ whereas $(S, S, S)$-1 remained unreacted (Scheme 8$)$.

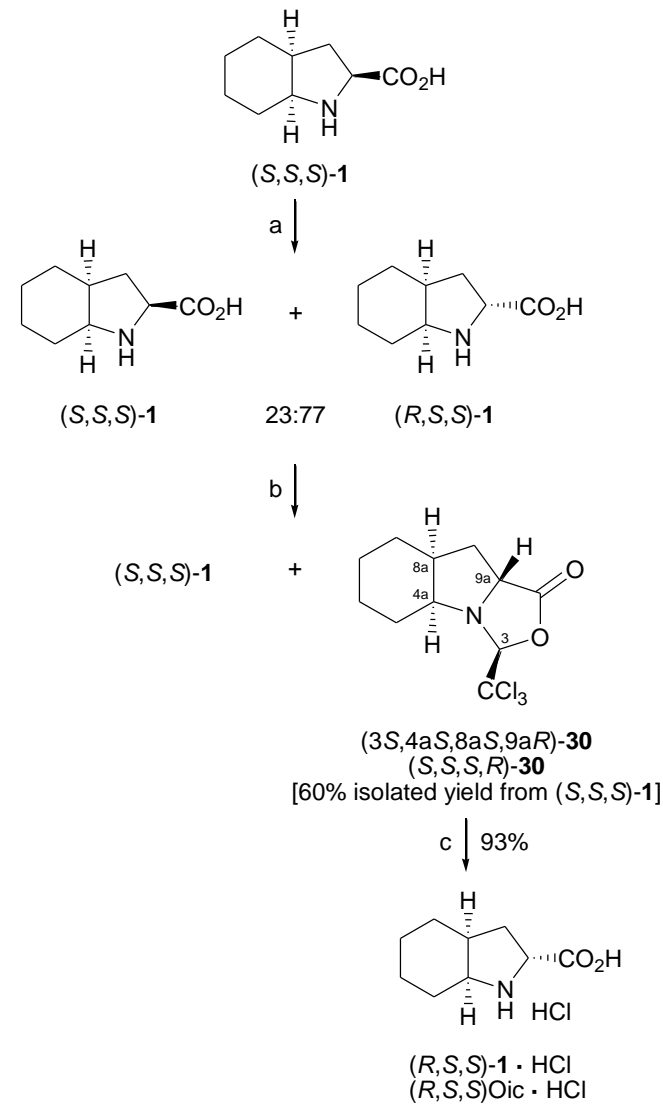

Scheme 8 . Synthesis of enantiomerically pure $(R, S, S)$ Oic according to ref. 19e. Reagents and conditions: a) Salicylaldehyde, $\mathrm{AcOH}$, reflux, $24 \mathrm{~h}$; b) $\mathrm{CCl}_{3} \mathrm{CHO}, \mathrm{CH}_{3} \mathrm{CN}$, r.t.; c) $3 \mathrm{~N} \mathrm{HCl} / \mathrm{EtOAc}$, r.t.

This novel separation procedure was inspired in reported investigations dealing with the highly stereoselective synthesis of bicyclic oxazolidinones derived from L-proline. ${ }^{[27]}$ The condensation of L-proline with bulky aldehydes leads to a single diastereomer with the bulky group in a cis disposition relative to the hydrogen at the $\alpha$ carbon. The ease of such stereoselective condensation, when applied to octahydroindole-2-carboxylic acids, proved to be conditioned to the structural constraint of the resulting tricyclic system. Presumably, the formation of the oxazolidinone from $(S, S, S)$-1 was precluded due to overlapping of hydrogen atoms that would occur at the concave face defined by the tricyclic scaffold. ${ }^{[19 e]}$

The single oxazolidinone produced, $(S, S, S, R)-\mathbf{3 0}$, was easily separated from unreacted $(S, S, S)$-1 by filtration through a short pad of silica and its stereochemistry was corroborated by X-ray diffraction analysis. ${ }^{[19 e]}$ Subsequent hydrolysis under acidic conditions allowed the isolation of the desired $(R, S, S)$ Oic (Scheme 8). Altogether, this combined epimerization-condensationhydrolysis sequence ${ }^{[19 \mathrm{e}]}$ provided a $56 \%$ overall yield of $(R, S, S)-\mathbf{1}$. This is a much higher efficiency than that corresponding to the combined epimerization-crystallizations method ${ }^{[19 c]}$ in Scheme 7 $(30 \%)$.

The ready accessibility to oxazolidinone $(S, S, S, R)$-30 made it feasible to explore the synthesis of $\alpha$-substituted Oic derivatives, capitalizing on Germanas' work performed on the trichloromethyloxazolidinone derived from L-proline, ${ }^{[27]}$ and based on pioneering studies by Seebach. ${ }^{[28]}$ These studies describe that the bridgehead nitrogen of the oxazolidinone derived from Lproline is strongly pyramidalized even when an enolate is generated and its inversion does not take place because of the high steric constraints that would be associated to this change. For this 
reason, the enolate attacks electrophiles only from the face previously occupied by the $\alpha$ hydrogen, thus leading to the formation of a single stereoisomer with complete retention of configuration at the $\alpha$ carbon. This behavior was named by Seebach as self-reproduction of chirality. ${ }^{[28]}$

On this basis, we carried out the preparation of enantiopure $(R, S, S)(\alpha \mathrm{Me}) \mathrm{Oic}^{[17]}$ starting from $(S, S, S, R)-\mathbf{3 0}$ (Scheme 9$){ }^{[19 \mathrm{e}]}$ The treatment of this oxazolidinone with lithium diisopropylamide generated an enolate that underwent alkylation with methyl iodide exclusively at the $\mathrm{Si}$ face. Single crystal X-ray diffraction analysis provided evidence for the alkylation reaction taking place with retention of configuration, that is, the trichloromethyl group and the newly introduced substituent are cis to each other on the exo side of the bicycle formed by the two five-membered rings. The resulting $\alpha$-methylated oxazolidinone $(S, S, S, R)$-31 was deprotected under acidic conditions to give the free $\alpha$-methylated amino acid $(R, S, S)(\alpha \mathrm{Me})$ Oic in excellent global yield. ${ }^{[19 \mathrm{e}]}$

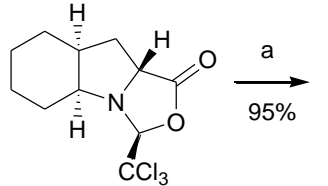

$(S, S, S, R)-30$

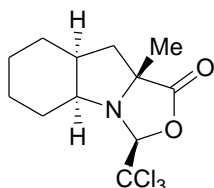

$(S, S, S, R)-\mathbf{3 1}$<smiles>O=C(O)[C@@]1(Cl)C[C@H]2CCCC[C@H]2N1</smiles>

$(R, S, S)-2 \cdot \mathrm{HCl}$

$(R, S, S)(\alpha \mathrm{Me}) \mathrm{Oic} \cdot \mathrm{HCl}$
Scheme 9. Synthesis of enantiomerically pure $(R, S, S)(\alpha \mathrm{Me})$ Oic according to ref. 19e. Reagents and conditions: a) LDA, MeI, THF, $-78{ }^{\circ} \mathrm{C}$ to $-50{ }^{\circ} \mathrm{C}$; b) $6 \mathrm{~N} \mathrm{HCl} / \mathrm{AcOH}$, reflux

The preparation of $(S, S, S)(\alpha \mathrm{Me}) \mathrm{Oic}$ required a different synthetic procedure because, as already mentioned, $(S, S, S)-\mathbf{1}$ failed to undergo condensation with trichloroacetaldehyde to produce the corresponding oxazolidinone, $(R, S, S, S)$-30 (Scheme 10$).^{[19 \mathrm{e}]}$ The alternative methodology for the preparation of $(S, S, S)(\alpha \mathrm{Me}) \mathrm{Oic}^{[15,29,30]}$ took advantadge of the steric hindrance introduced by the cyclohexane group in $(S, S, S)$-1, which prevented the formation of the oxazolidinone, to induce facial selectivity on $\alpha$-alkylations taking place on an exocyclic enolate. Such an enolate was generated from the $N$-Boc protected amino ester $(S, S, S)-\mathbf{2 5}$ upon treatment with lithium diisopropylamide and reacted with methyl iodide to provide a diastereoisomeric mixture of the $\alpha$ methylated compounds in 89:11 ratio (Scheme 10). ${ }^{[29,30]}$ The major isomer was isolated pure in $75 \%$ yield after column chromatography. Subsequent saponification provided $(S, S, S)(\alpha \mathrm{Me})$ Oic in the $N$-Boc protected form.

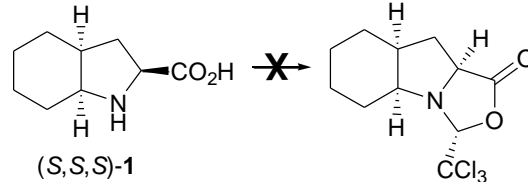

$\mathrm{a}, \mathrm{b} \downarrow 89 \%$

$(R, S, S, S)-\mathbf{3 0}$<smiles>CC(=O)OC(=O)[C@@H]1C[C@@H]2CCCC[C@H]2N1C(=O)OC(C)(C)C</smiles>

$(S, S, S)-25$

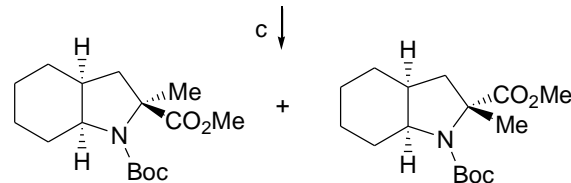

$(S, S, S)-32$

$89: 11$

$(R, S, S)-32$

(75\% isolated yield)

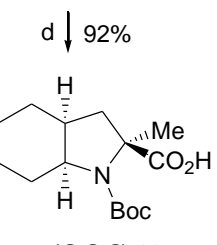

$(S, S, S)-33$

Boc- $(S, S, S)(\alpha \mathrm{Me})$ Oic

Scheme 10 . Synthesis of an $(S, S, S)(\alpha \mathrm{Me})$ Oic derivative in enantiomerically pure form, according to ref. 29,30. Reagents and conditions: a) $\mathrm{SOCl}_{2}$, $\mathrm{MeOH}$, r.t.; b) $\mathrm{Boc}_{2} \mathrm{O}, i \operatorname{Pr}_{2} \mathrm{EtN}$, DMAP, THF, r.t.; c) LDA, MeI, THF, -78 to $-50{ }^{\circ} \mathrm{C}$; d) $1 \mathrm{~N} \mathrm{KOH}, \mathrm{MeOH}$, reflux.

Interestingly, the $\alpha$-methylation reaction provided an identical result when performed on epimeric $(R, S, S)-25$ (Scheme 11) prepared from enantiopure $(R, S, S)-\mathbf{1} .^{[19 \mathrm{e}]}$ This observation indicates that both epimers give rise to the same intermediate enolate and that the stereocontrol during the $\mathrm{C}-\mathrm{C}$ bond forming reaction is purely driven by the steric hindrance imposed by the cis-fused cyclohexane group. Such an efficient facial stereodifferentiation translated into a preferential formation of $(S, S, S)$-32. The minor stereoisomer, $(R, S, S)$-32, matched a derivative which was separately prepared from enantiomerically pure $(R, S, S)$-2 (Scheme $9)$, thus confirming the $(S, S, S)$ stereochemistry of the major $\alpha$ methylation product in Schemes 10 and 11.

It is worth mentioning that the complementary methodologies described for the preparation of $(R, S, S)(\alpha \mathrm{Me}) \mathrm{Oic}$ and $(S, S, S)(\alpha \mathrm{Me}) \mathrm{Oic}$ in Schemes 9 and 10, respectively, have proven effective for the incorporation of other electrophiles at the $\alpha$ carbon, regardless of their steric and electronic characteristics. ${ }^{[19 e, 30]}$ 


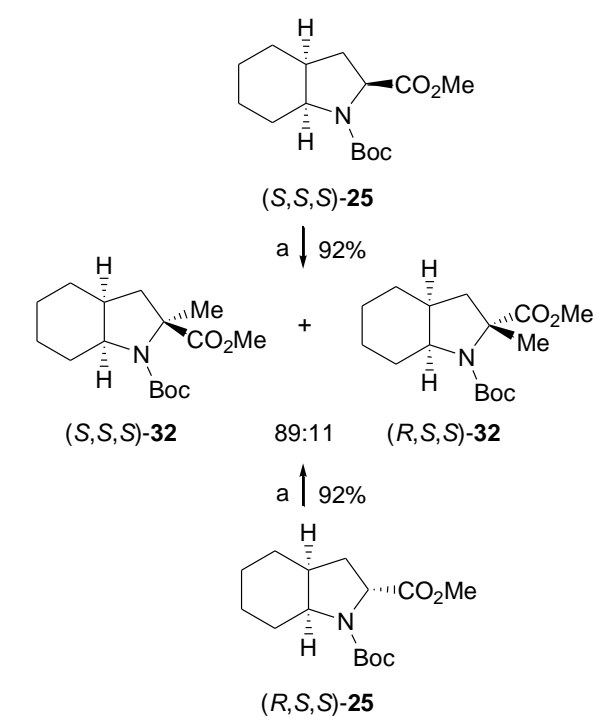

Scheme 11. $\alpha$-Methylation of enantiomerically pure $(S, S, S)$ Oic and $(R, S, S)$ Oic derivatives described in ref. 30 . Reagents and conditions: a) LDA, MeI, THF, -78 to $-50{ }^{\circ} \mathrm{C}$.

An analysis of the asymmetric synthetic procedures described above provides evidence that all the cis-fused stereoisomers of Oic and $(\alpha \mathrm{Me})$ Oic depicted in Figure 7 can be derived in a quite efficient manner from the same starting product, namely $(S)$ indoline-2-carboxylic acid $[(S)-\mathbf{2 8}]$ or its enantiomer $[(R)-28]$. In particular, $(S)$-28 proved the most advantageous precursor for the preparation of $(S, S, S)$ Oic, as shown in Scheme 6. In turn, this Oic stereoisomer has been employed as a substrate for the synthesis of $(S, S, S)(\alpha \mathrm{Me})$ Oic through a stereoreselective $\alpha$-methylation reaction (Scheme 10). $(S, S, S)$ Oic has also been transformed into $(R, S, S)$ Oic by means of an epimerization process (Scheme 8$)$, and then into $(R, S, S)(\alpha \mathrm{Me}) \mathrm{Oic}$ (Scheme 9). Obviously, the use of $(R)$ 28 as the starting material would provide access to the enantiomeric products. The usefulness of $(S)$ - and $(R)-\mathbf{2 8}$ in the production of all the possible stereoisomers of Oic and $(\alpha \mathrm{Me}) \mathrm{Oic}$ characterized by a cis ring junction in optically pure form is illustrated in Scheme 12.
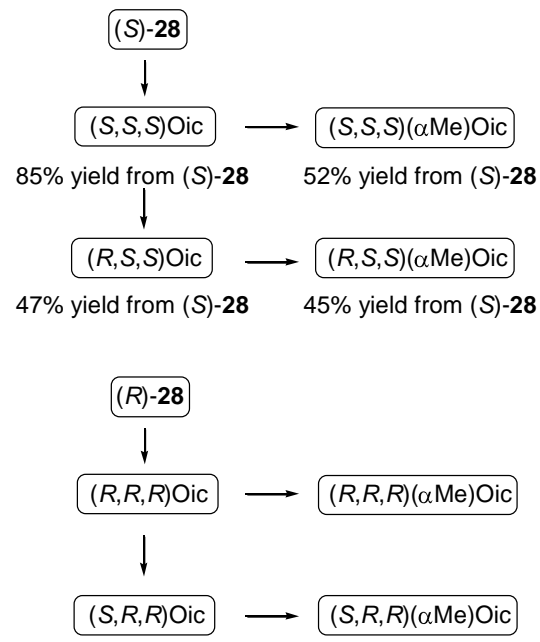

Scheme 12. Schematic representation of the accessibility to all cis-fused Oic and $(\alpha \mathrm{Me})$ Oic stereoisomers in enantiomerically pure form starting from $(S)$ - or $(R)$-indoline-2-carboxylic acid. Overall yields calculated from $(S)-\mathbf{2 8}$ are provided for the synthesis of the target amino acids in the free form or as $N$-protected derivatives.

Both $(R)$ - and $(S)-\mathbf{2 8}$ are accessible starting materials because their synthesis has been actively investigated. ${ }^{[31]}$ The interest on these compounds stems from the fact that the indoline scaffold is found in a wide range of alkaloid natural products, ${ }^{[32]}$ biologically active compounds, ${ }^{[33]}$ and as a part of chiral auxiliaries for asymmetric synthesis. ${ }^{[34]}$ In particular, the preparation of $(R)$ - or $(S)$-indoline-2-carboxylic acid has been achieved by chemical resolution with diverse crystallizing agents, ${ }^{[19 \mathrm{a}, \mathrm{c}, 20 \mathrm{a}, 35]}$ chemical synthesis through catalytic asymmetric hydrogenation of indoles, ${ }^{[36]}$ intramolecular aryl aminations, ${ }^{[37]}$ asymmetric deprotonation of $N$-Boc indoline followed by carbonylation, ${ }^{[38]}$ and via enzymatic methods. ${ }^{[39]}$ Moreover, both $(R)$ - and $(S)$-28 have become commercially available.

\section{Resolution procedures}

Resolution procedures may result in a convenient alternative to asymmetric synthesis, in particular, when the isolation of the two enantiomers of a certain stereoisomer is pursued. Among the different procedures that allow the separation of enantiomers, chemical resolutions often provide moderate yields of optically pure material after extensive crystallizations and require working on a relatively large scale. This is the reason why enzymatic and chromatographic resolutions are becoming usual techniques for the production of enantiomerically pure compounds.

\subsection{Chemical resolutions}

Crystallizations of diastereoisomeric salts of different $\left(S^{*}, S^{*}, S^{*}\right)$ Oic derivatives have been reported.$^{[18,21 c, 40]}$ In particular, Blankley et al achieved ${ }^{[18 \mathrm{~b}, \mathrm{c}]}$ the resolution of the racemic $N$ benzoyl derivative $\left(S^{*}, S^{*}, S^{*}\right)$-36 by separation of the diastereomeric salts of $(S)$ - $\alpha$-phenylethylamine by means of crystallizations (Scheme 13). The L-tartrate salts of the tert-butyl ester derivative $\left(S^{*}, S^{*}, S^{*}\right)-37$ also proved useful for the same purpose. The process was laborious in both cases and suffered from low isolated yields given that several crystallizations were necessary. The acidic hydrolysis of the $(S)$ - $\alpha$-phenylethylamine salt isolated from $\left(S^{*}, S^{*}, S^{*}\right)$-36 provided the all-cis fused Oic stereoisomer exhibiting levorotatory optical activity. Conversely, the hydrolysis of the L-tartatre salt derived from $\left(S^{*}, S^{*}, S^{*}\right)-37$ rendered the levorotatory tert-butyl ester derivative. Even if no further details were given by the authors ${ }^{[18 b, c]}$ concerning the assignment of absolute configurations, the isolated compounds can be identified as $(S, S, S)-\mathbf{1}$ and $(S, S, S)-\mathbf{3 7}$, respectively, by comparison of their optical rotations to values reported in the literature. ${ }^{[20 \mathrm{a}, 25]}$

The preparation of the racemic precursors $\left(S^{*}, S^{*}, S^{*}\right)-36$ and $\left(S^{*}, S^{*}, S^{*}\right)-\mathbf{3 7}$ was achieved by hydrogenation of the indole ester $\mathbf{3 4}$ under acidic conditions, using rhodium/carbon as the catalyst (Scheme 13). ${ }^{[18 b, c]}$ The use of this starting material showed the advantage of providing a unique Oic stereoisomer, namely, that exhibiting a cis relative disposition of the two bridgehead hydrogen atoms and that at the $\alpha$ position, whereas, as mentioned above, the hydrogenation of indoline-2-carboxylic acid (28) affords a 10\% of the epimer at the $\alpha$ carbon (Scheme 6). In spite of this advantage, only a $32 \%$ overall isolated yield of racemic $\left(S^{*}, S^{*}, S^{*}\right)$-1 from 34 was reported. ${ }^{[18 b, c]}$ Such a poor yield was mainly due to an inefficient recrystallization of the hydrochloride salt of $\left(S^{*}, S^{*}, S^{*}\right)$ $\mathbf{3 5}$ prior to the ester hydrolysis.

In addition, the chemical resolution of the benzyl ester derivative of $\left(S^{*}, S^{*}, S^{*}\right)-\mathbf{1}$ using either dibenzoyl-L-tartaric acid or $N$-Cbz protected L-phenylalanine as the resolving agents has been outlined in patents. ${ }^{[21 c, 40]}$ However, insufficient information about the 
assignment of the absolute configuration of the isolated enantiomers or the stereochemical integrity of the racemic precursors is provided.

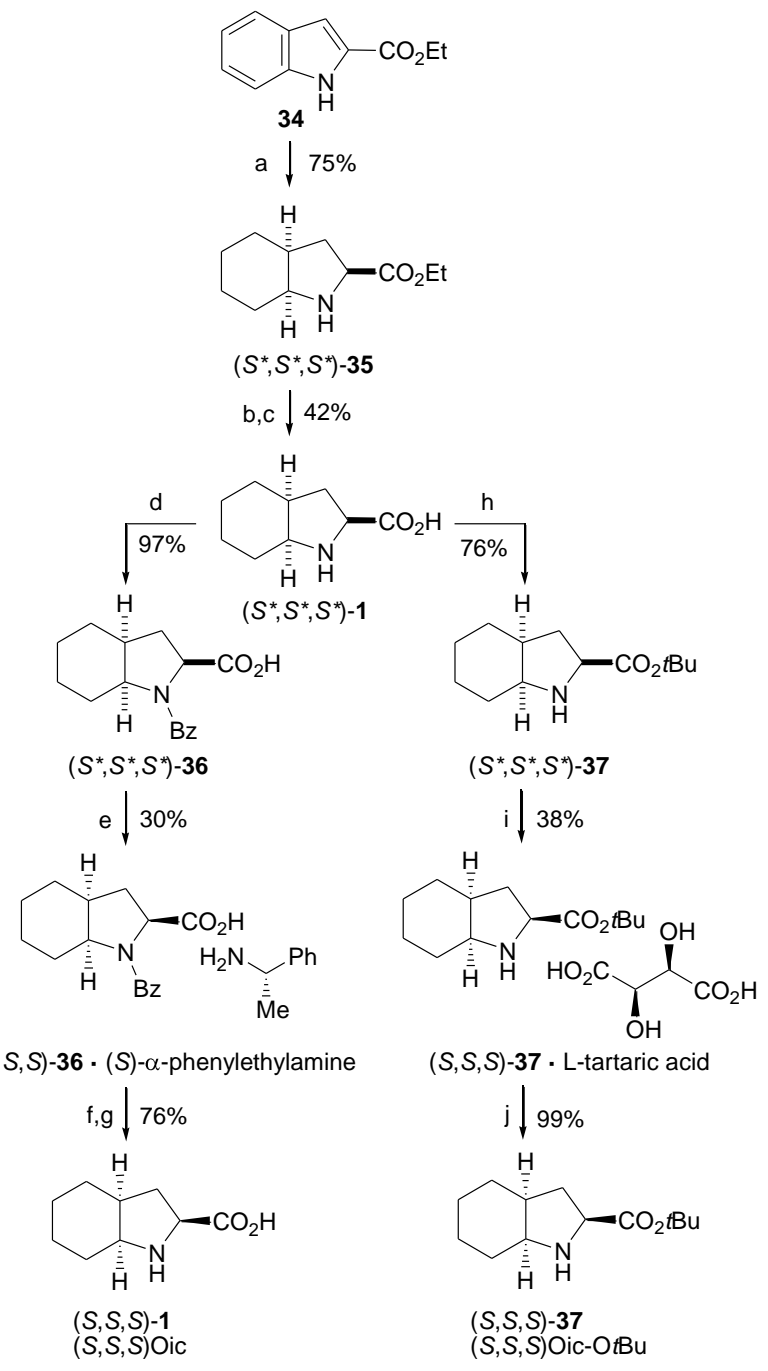

Scheme 13. Synthesis of $(S, S, S)$ Oic derivatives in enantiomerically pure form by chemical resolution, according to ref. $18 \mathrm{~b}$. Reagents and conditions: a) $\mathrm{H}_{2}$ (Parr apparatus), conc. $\mathrm{H}_{2} \mathrm{SO}_{4}, 10 \% \mathrm{Rh} / \mathrm{C}$, EtOH; b) aq. $\mathrm{HCl} 15 \%$, reflux; recrystallization from $\mathrm{CH}_{3} \mathrm{CN} / \mathrm{EtOAc}$; c) aq. $\mathrm{NaOH}$; recrystallization from $\mathrm{CH}_{3} \mathrm{CN}$; d) $2 \mathrm{~N} \mathrm{NaOH}, \mathrm{BzCl}, \mathrm{H}_{2} \mathrm{O}, 5{ }^{\circ} \mathrm{C}$; recrystallization from $\mathrm{EtOH} / \mathrm{H}_{2} \mathrm{O}$; e) $(S)$ - $\alpha$-phenylethylamine, $\mathrm{MeOH}$; then EtOAc; recrystallization from $\mathrm{MeOH} / \mathrm{EtOAc}$; f) $\mathrm{HCl}, \mathrm{MeOH} / \mathrm{H}_{2} \mathrm{O}$, r.t.; g) conc. $\mathrm{HCl}, \mathrm{H}_{2} \mathrm{O}$, reflux; filtration through Amberlite IR-120; two recrystallizations from $\mathrm{MeOH} / \mathrm{EtOH}$; h) isobutylene, conc. $\mathrm{H}_{2} \mathrm{SO}_{4}$, dioxane, r.t., sealed tube; i) L-tartaric acid, THF; recrystallization from $\mathrm{EtOAc} / \mathrm{MeOH}, 0^{\circ} \mathrm{C} ;$ j) aq. $\mathrm{Na}_{2} \mathrm{CO}_{3} 5 \%, \mathrm{Et}_{2} \mathrm{O}$

\subsection{Enzymatic resolutions}

Enzymatic processes for producing optically active Oic derivatives have been addressed only recently and just two successful examples have been described to date. Hirata et al disclosed in a patent ${ }^{[41]}$ an efficient resolution of the ethyl ester $\left(S^{*}, S^{*}, S^{*}\right)-\mathbf{3 8}$ by hydrolysis with an esterase, derived from a Chromobacterium SC-YM-1 strain, working in an aqueous solution buffered at $\mathrm{pH} 8$ (Scheme 14). The process allowed the isolation of enantiopure $(S, S, S)-39$ in $49 \%$ yield. Conversely, the optical purity of the unreacted ester, $(R, R, R)-\mathbf{3 8}$, was slightly lower ( $96 \%$ ee). Under similar conditions, the same enzyme was also able to asymmetrically hydrolyze the ester group of the $N$-Boc protected derivative $\left(S^{*}, S^{*}, S^{*}\right)$-40, thus allowing the production of enantiopure $(S, S, S)-\mathbf{4 1}$ in $45 \%$ yield. The $(R, R, R)$ enantiomer of the starting ester was recovered in $39 \%$ yield and high optical purity. Despite the fact that no details were provided about the assignment of the absolute configuration of each enantiomer, the acids formed are claimed to be $(S, S, S)$.

The racemic substrates used for the aforementioned enzymatic resolutions were prepared ${ }^{[41]}$ by protection of the amino moiety in $\left(S^{*}, S^{*}, S^{*}\right)-35$ (Scheme 13) with $\mathrm{Cbz}$ or Boc using standard procedures. In turn, the latter compound was obtained by hydrogenation of the indole derivative $\mathbf{3 4}$ under slightly different conditions to those reported in Scheme $13\left[\mathrm{H}_{2}\right.$ (4 bar), conc. $\mathrm{H}_{2} \mathrm{SO}_{4}$, $5 \% \mathrm{Rh} / \mathrm{C}, \mathrm{EtOH}, 60^{\circ} \mathrm{C}, 10 \mathrm{~h} ; 83 \%$ yield].

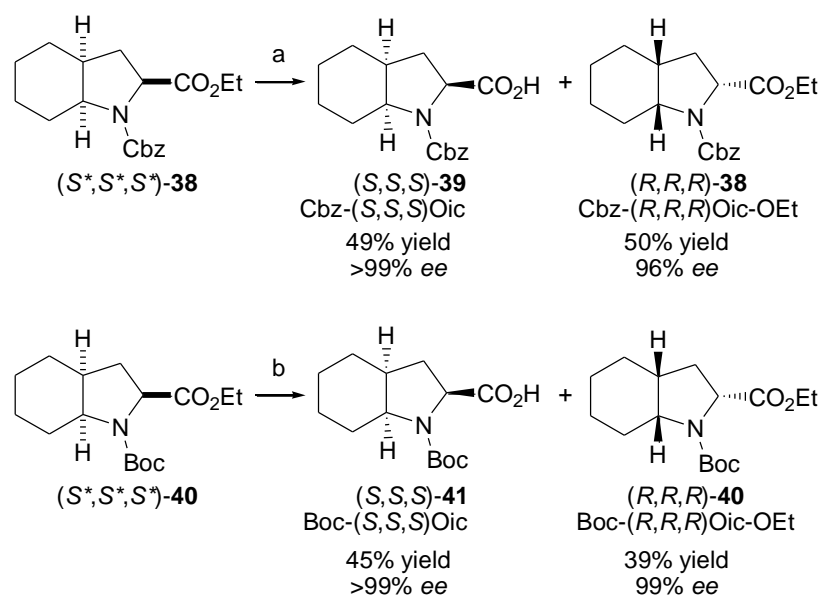

Scheme 14. Synthesis of $(S, S, S)$ and $(R, R, R)$ Oic derivatives in enantiomerically pure form by enzymatic resolution, according to ref. 41 . Reagents and conditions: a) Esterase 160A189Y363term derived from Chromobacterium SC-YM-1 strain, phosphate buffer pH 8, $30^{\circ} \mathrm{C}, 30 \mathrm{~h}$; b) Esterase 160A189Y363term derived from Chromobacterium SC-YM-1 strain, phosphate buffer $\mathrm{pH} 8,30^{\circ} \mathrm{C}, 40 \mathrm{~h}$.

More recently, we reported ${ }^{[39 a]}$ an alternative enzymatic resolution of a racemic $\left(S^{*}, S^{*}, S^{*}\right)$ Oic derivative (Scheme 15). The methodology employed a lipase for enantiomer discrimination during a highly selective carbamate formation. Candida antarctica lipase type A exhibited high enantioselectivity towards both the methyl and benzyl esters derived from $\left(S^{*}, S^{*}, S^{*}\right)-\mathbf{1}$ when using diallyl carbonate as the alkoxycarbonylating agent and working in tert-butyl methyl ether. However, the activity showed by the lipase was superior for the more sterically hindered benzyl ester, $\left(S^{*}, S^{*}, S^{*}\right)-42$ (Scheme 15$)$. In this case, the reaction proceeded highly efficiently, with an E-value $>200$ and a $50 \%$ conversion, thus providing excellent yields of the starting material $(R, R, R)-\mathbf{4 2}$ and the $N$-allyloxycarbonyl derivative $(S, S, S)-\mathbf{4 3}$, which were isolated in high optical purity. The absolute configurations of both compounds were assigned after transformation of $(R, R, R)-\mathbf{4 2}$ into a derivative of known stereochemistry. ${ }^{[39 a]}$

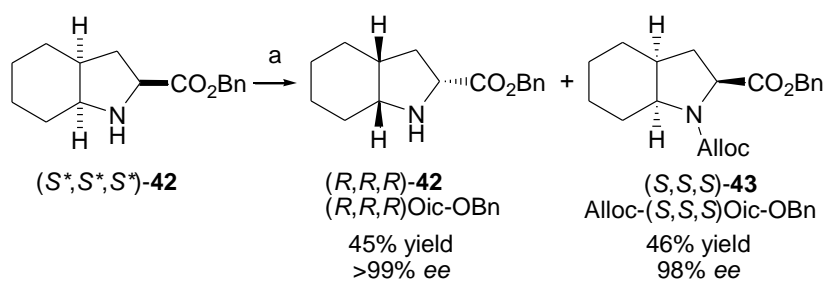

Scheme 15. Synthesis of $(S, S, S)$ and $(R, R, R)$ Oic derivatives in enantiomerically pure form by enzymatic resolution, according to ref. 39a. Reagents and conditions: a) Diallyl carbonate, candida antarctica lipase type A, $t \mathrm{BuOMe}, 30^{\circ} \mathrm{C}, 250 \mathrm{rpm}, 72 \mathrm{~h}$. 
The preparation of the starting racemic benzyl ester $\left(S^{*}, S^{*}, S^{*}\right)$ 42 is described in the next section.

In contrast to the excellent resolution achieved for the $\left(S^{*}, S^{*}, S^{*}\right)$ Oic stereoisomer, the lipase-catalysed process failed to resolve several racemic derivatives of $\left(R^{*}, S^{*}, S^{*}\right)$ Oic. ${ }^{[42]}$ Although a good conversion was achieved during the carbamate formation also in this case, the optical purity of the resulting compounds was poor. ${ }^{[42]}$ On the other hand, no attempt to enzymatically resolve any $(\alpha \mathrm{Me})$ Oic-based substrate has been described, presumably because the increased steric crowding at the $\alpha$ carbon would limit the access to the active site of enzymes, as happens for most $\alpha$ tetrasubstituted $\alpha$-amino acids. ${ }^{[43]}$

\subsection{Chromatographic resolutions}

High performance liquid chromatography (HPLC) using chiral stationary phases is nowadays considered a very useful tool for producing enantiomerically pure compounds both in the academic and industrial fields. ${ }^{[44]}$ In this context, our group has developed ${ }^{[45]}$ efficient methodologies for the preparation of significant quantities of a variety of unnatural amino acids in optically pure form by performing HPLC resolution of racemic precursors on chiral columns.

The efficiency of the resolution procedures carried out in our ${ } \mathrm{ab}^{[45]}$ relies on the use of columns containing polysaccharidederived stationary phases in which the chiral selector is covalently bonded to the silica gel matrix. These so-called immobilized phases have recently become commercially available as Chiralpak ${ }^{\circledR}{ }^{\circledR A},{ }^{[46]}$ $\mathrm{IB}^{[47]}$ and $\mathrm{IC}^{[48]}$ (the first HPLC resolutions carried out in our group used columns of this type made in the laboratory) and combine the advantages of the traditional coated polysaccharidederived phases with the robustness associated to covalent linkage. ${ }^{[46-50]}$ They are therefore characterized by an excellent chiral recognition ability together with a remarkable loading capacity and wide solvent compatibility. The two latter points are of particular relevance when separations on a preparative scale are envisaged, because the solubility of the sample on the eluent is crucial to achieve high efficiency. The Chiralpak ${ }^{\circledR}$ columns mentioned above are stable in the presence of all organic solvents, at variance with non-immobilized polysaccharide-derived phases, which are compatible only with hydrocarbon/alcohol mixtures. Needless to say, the latter combination of solvents is not appropriate to reach high concentrations of most organic compounds, which means a clear limitation for preparative purposes.

Recently, we have applied this technique to gain access to all Oic and $(\alpha \mathrm{Me})$ Oic stereoisomers depicted in Figure 7 in optically pure form and multigram quantities. In all cases, the HPLC resolution was carried out on a racemic precursor of the target amino acid bearing the carboxylic acid and amino moieties adequately protected. Several aspects were taken into account to appropriately select the protecting groups. Firstly, these groups should be introduced through simple high-yielding transformations or, even better, be already present during the synthetic pathway. Such protecting groups should be also removable under mild reaction conditions that do not risk the optical purity of the resolved material if subsequent synthetic transformations are necessary. This issue is of particular relevance in the case of Oic derivatives, where an epimerization-prone $\alpha$-proton is present. Other considerations for appropriate selection of the protecting groups included the ease of monitoring the chromatographic process by UV detection as well as the effect of the derivatization on solubility. The latter point is crucial for performing preparative- scale chromatography, in which case, the loading capacity of the column, and therefore the efficiency of the process, depend dramatically on the solubility of the sample in the mobile phase as well as in the solvent used for injection. On these bases, protecting groups of the carbamate type typically employed for peptide synthesis were used for the amino moiety while the carboxylic acid was derivatized as an ester. Accordingly, different combinations of the Boc or $\mathrm{Cbz} N$-protecting groups and the methyl or benzyl esters were tested for the racemic precursors of Oic and $(\alpha \mathrm{Me})$ Oic to be resolved (for the Oic derivatives the methyl ester was not considered to avoid the risk of epimerization at the $\alpha$ position in the subsequent saponification step).

The resolution of the different derivatives prepared from each Oic and $(\alpha \mathrm{Me})$ Oic stereoisomer was initially tested at the analytical level in $250 \times 4.6 \mathrm{~mm}$ ID Chiralpak ${ }^{\circledR}$ IA, IB and IC columns using mixtures of $n$-hexane/isopropanol as the eluent. The effect produced by the addition of different percentages of other solvents (such as acetone, chloroform or tert-butyl methyl ether) to the mobile phase was also tested. This screening revealed the compounds depicted in Figure 9 to be the most convenient derivatives to be subjected to preparative chromatographic resolution. Among the $\left(S^{*}, S^{*}, S^{*}\right)$ Oic precursors tested, the best separation was observed for that bearing the Boc and benzyl ester groups when injected into the IA column, whereas IB showed the best chiral distinction capability for the $\left(R^{*}, S^{*}, S^{*}\right)$ Oic derivative containing a $\mathrm{Cbz}$ group. As mentioned above, only the benzyl ester was tested for the Oic substrates. In comparison, both the benzyl and methyl esters were considered for the $(\alpha \mathrm{Me})$ Oic derivatives, with the latter leading to superior enantioseparations, particularly, on the IC column.<smiles>O=C(OCc1ccccc1)C1CC2CCCCC2N1C(=O)c1ccccc1</smiles>

$\left(S^{*}, S^{*}, S^{*}\right)-44$<smiles>COC(=O)N1C[C@H]2CCCC[C@H]2C[C@]1(C)O</smiles>

$\left(S^{*}, S^{*}, S^{*}\right)-46$<smiles>O=C(Cc1ccccc1)C1CC2CCCCC2N1C(=O)OCc1ccccc1</smiles>

$\left(R^{*}, S^{*}, S^{*}\right)-45$<smiles></smiles>

$\left(R^{*}, S^{*}, S^{*}\right)-46$
Figure 9. Racemic Oic and $(\alpha \mathrm{Me})$ Oic derivatives subjected to preparativescale HPLC resolution on chiral columns.

It is worth mentioning that the three columns used are considered somehow complementary and, indeed, complete baseline separation of peaks was achieved for almost all the compounds tested in at least one of them. In any case, since these assays were not intended for analytical purposes but to be extended to a preparative scale, maximum peak resolution was pursued. In some cases, addition of a cosolvent to the initial $n$ hexane/isopropanol eluent mixture proved highly detrimental to the separation or resulted in enhanced enantiodiscrimination but at the cost of significant peak broadening. However, in other cases, the presence of tert-butyl methyl ether in the mobile phase led to the improvement of both factors, together with increased sample solubility. Table 1 lists the final optimized conditions established at the analytical level for the resolutions of the Oic and $(\alpha \mathrm{Me}) \mathrm{Oic}$ derivatives depicted in Figure 9. ${ }^{[51-53]}$ The chromatographic profiles obtained under such conditions are shown in Figure 10 Resolution factors $\left(R_{\mathrm{S}}\right)$ ranging from 3.1 to 9.5 were reached, thus 
evidencing the high chiral recognition ability of the columns and providing an excellent groundwork for the next preparative stage.

Table 1. Optimized conditions for the HPLC enantioseparation of Oic and $(\alpha \mathrm{Me})$ Oic derivatives at the analytical level. ${ }^{[a]}$

\begin{tabular}{lclllll}
\hline Compound $^{[\mathrm{b}]}$ & \multicolumn{2}{c}{ Column } & \multicolumn{1}{c}{ Mobile phase $(\mathrm{v} / \mathrm{v})$} & $k^{\prime}$ & $\alpha$ & $R_{\mathrm{S}}$ \\
\hline$\left(S^{*}, S^{*}, S^{*}\right)-\mathbf{4 4}$ & IA & $n \mathrm{Hx} / i \mathrm{PrOH} / \mathrm{BuOMe} 91 / 3 / 6$ & 1.0 & 2.5 & 9.5 \\
$\left(R^{*}, S^{*}, S^{*}\right)-\mathbf{4 5}$ & IB & $n \mathrm{Hx} / i \mathrm{PrOH} 95 / 5^{[\mathrm{cc}}$ & 1.9 & 1.8 & 3.1 \\
$\left(S^{*}, S^{*}, S^{*}\right)-\mathbf{4 6}$ & IC & $n \mathrm{Hx} / i \mathrm{PrOH} / t \mathrm{BuOMe} 50 / 6 / 44$ & 1.3 & 1.9 & 6.7 \\
$\left(R^{*}, S^{*}, S^{*}\right)-46$ & IC & $n \mathrm{Hx} / i \mathrm{PrOH} / \mathrm{BuOMe} 65 / 10 / 25$ & 1.5 & 2.1 & 6.0 \\
\hline
\end{tabular}

${ }^{\text {[a] }}$ Chiralpak $^{\circledR}$ IA, IB, and IC columns $(250 \times 4.6 \mathrm{~mm}$ ID) were used. The chromatographic profiles are shown in Figure 10. Conditions: flow rate, 0.8 $\mathrm{mL} / \mathrm{min}$ (unless otherwise indicated); temperature, $25^{\circ} \mathrm{C}$; UV detection, $210 \mathrm{~nm}$. The capacity $\left(k^{\prime}\right)$, selectivity $(\alpha)$ and resolution $\left(R_{\mathrm{S}}\right)$ factors are defined as follows: $k^{\prime}=\left(t_{r}-t_{0}\right) / t_{0}, \alpha=k_{2}^{\prime} / k_{1}^{\prime}, R_{\mathrm{S}}=1.18\left(t_{2}-t_{1}\right) /\left(w_{2}+w_{1}\right)$, where subscripts 1 and 2 refer to the first and second eluted enantiomers, $t_{r}$ $(r=1,2)$ are their retention times, and $w_{1}$ and $w_{2}$ denote their half-height peak widths; $t_{0}$ is the dead time. ${ }^{[b]}$ See Figure $9 .{ }^{[c]}$ Flow rate, $0.9 \mathrm{~mL} / \mathrm{min}$.
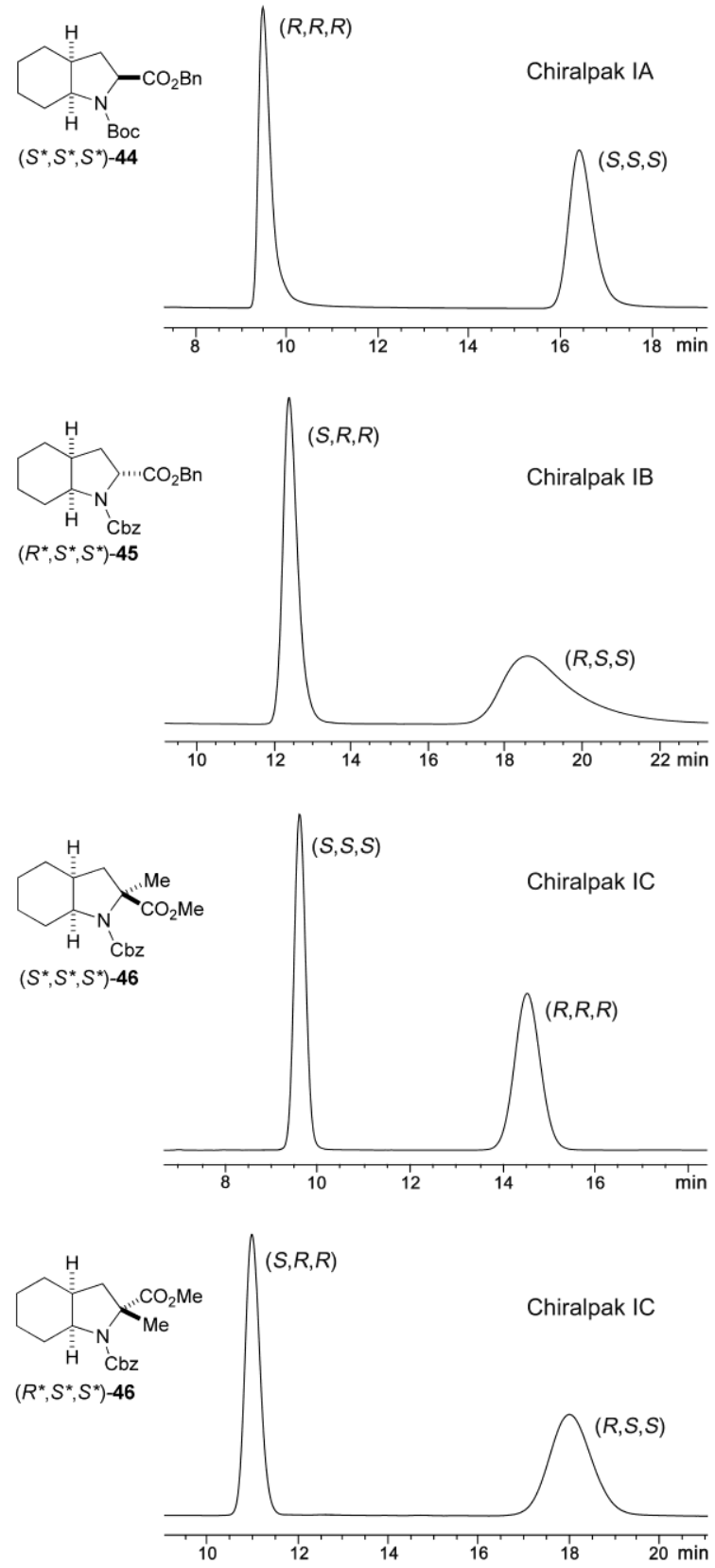

Figure 10. Chromatographic profiles corresponding to the analytical HPLC resolutions presented in Table 1 for the racemic Oic and $(\alpha \mathrm{Me})$ Oic derivatives in Figure 9. These enantioseparation conditions were selected for subsequent extension to the preparative scale.

Extension to the preparative scale was performed by scaling up the conditions established at the analytical level (Table 1, Figure 10) to $250 \times 20 \mathrm{~mm}$ ID Chiralpak ${ }^{\circledR}$ IA, IB or IC columns containing near 20-fold the amount of chiral stationary phase present in the analytical ones. Prior to carrying out each preparative separation, the loading capacity was established by working in an overload mode on the analytical-sized column under the conditions given in Table 1. This step allowed us to determine the maximum amount of sample that the column could hold while maintaining the separation of peaks. After this value was established, a 20 -fold scaling allowed direct translation into the preparative scale.

The preparative resolution of $\left(S^{*}, S^{*}, S^{*}\right)-\mathbf{4 4}$ is described next, as an example. The separation was carried out ${ }^{[51]}$ by successive injections of the racemate on a $250 \times 20 \mathrm{~mm}$ ID Chiralpak ${ }^{\circledR}$ IA column using a mixture of $n$-hexane/isopropanol/tert-butyl methyl ether $91 / 3 / 6$ as the eluent and working at a flow rate of $16 \mathrm{~mL} / \mathrm{min}$ Detection was carried out by UV monitoring at $220 \mathrm{~nm}$. Each injection consisted in $0.8 \mathrm{~mL}$ of a highly concentrated solution of the racemate in chloroform (500 $\mathrm{mg}$ of sample per $\mathrm{mL}$ of solvent) and was repeated every 14 minutes. The profile of one of such injections is shown in Figure 11.

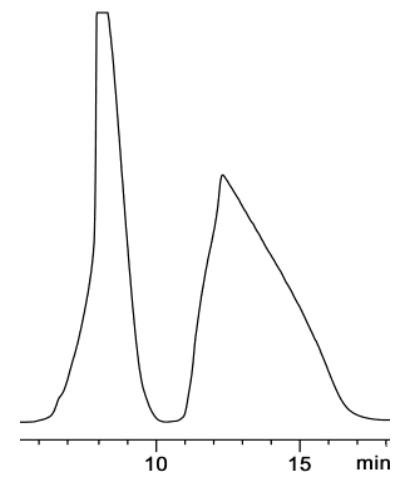

Figure 11. Preparative HPLC resolution of racemic $\left(S^{*}, S^{*}, S^{*}\right)-\mathbf{4 4}$. Profile corresponding to the injection of $800 \mu \mathrm{L}$ of $\left(S^{*}, S^{*}, S^{*}\right)-\mathbf{4 4}$ dissolved in chloroform (concentration: $500 \mathrm{mg}$ solute $/ \mathrm{mL}$ solvent). Column: Chiralpak $^{\circledR}$ IA $(250 \times 20 \mathrm{~mm}$ ID). Eluent: $n \mathrm{Hx} / i \mathrm{PrOH} / t \mathrm{BuOMe} 91 / 3 / 6$. Flow rate: $16 \mathrm{~mL} / \mathrm{min}$. UV detection: $220 \mathrm{~nm}$. The absorbance of the first peak is beyond the detector limit.

Following this protocol, a total of $4.650 \mathrm{~g}$ of $\left(S^{*}, S^{*}, S^{*}\right)-\mathbf{4 4}$ were subjected to this resolution process in about 3.5 hours time. The product eluted was collected in three separate fractions. Evaporation of the first and third fractions provided 2.300 and $2.298 \mathrm{~g}$ of the first and second eluted enantiomer, respectively, both of them in optically pure form (Figure 12), while the second fraction was found to contain $29 \mathrm{mg}$ of a $26: 74$ mixture enriched on the second enantiomer and was discarded. Therefore, as much as $4.60 \mathrm{~g}$ of optically pure material was isolated from a total of $4.65 \mathrm{~g}$ of injected racemate (that is, $99 \%$ recovering) in a single passage through the column. It should be noted that this efficient resolution process was carried out on a column size considered to be semi-preparative, which yet allowed the production of more than $1.2 \mathrm{~g}$ of enantiomerically pure compounds per hour. 

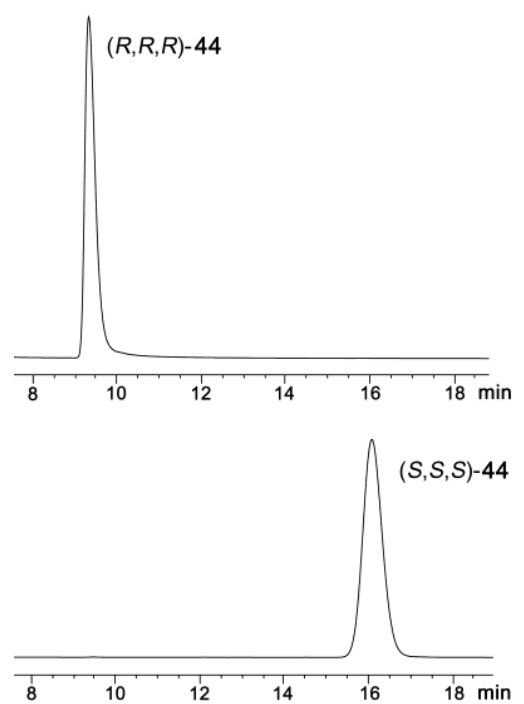

Figure 12. HPLC analytical profile of the resolved enantiomers of $\left(S^{*}, S^{*}, S^{*}\right)-44$. Column: Chiralpak ${ }^{\circledR}$ IA $(250 \times 4.6 \mathrm{~mm}$ ID). Eluent: $n \mathrm{Hx} / i \mathrm{PrOH} / t \mathrm{BuOMe}$ 91/3/6. Flow rate: $0.8 \mathrm{~mL} / \mathrm{min}$. UV detection: $210 \mathrm{~nm}$.

Extension of the analytical conditions given in Table 1 (Figure 10) to the preparative scale also proved very efficient for the remaining Oic and $(\alpha \mathrm{Me})$ Oic derivatives in Figure $9 .^{[52,53]} \mathrm{In}$ each case, the resolution process was applied to $3.4-4.7 \mathrm{~g}$ of racemate. A minimum of $95 \%$ of the starting racemic material was isolated in enantiomerically pure form after a single passage through the column. In all cases, the sample was injected dissolved in chloroform at a concentration ranging from 500 to $600 \mathrm{mg}$ of solute per $\mathrm{mL}$ of solvent. It should be emphasized that this extremely high sample concentration was essential to the high performance of the resolution process. As stated before, the use of chloroform is compatible with immobilized polysaccharide-derived stationary phases of the Chiralpak ${ }^{\circledR}$ type but not with the coated ones previously available on the market.

Scheme 16 shows the transformation of the enantiomerically pure compounds isolated after the HPLC resolution step into the target amino acids, either in the free form or as $N$-protected derivatives. In all cases, the first eluted enantiomer is drawn at the upper position. The absolute stereochemistry of the enantiomerically pure compounds was established by comparison of either their specific rotations or their HPLC retention times to those determined for enantiopure samples obtained by asymmetric synthesis procedures (Schemes 6, 8-10).

Accordingly, more than $1.50 \mathrm{~g}$ of each Oic and $(\alpha \mathrm{Me})$ Oic stereoisomer shown in Figure 7 (as such or bearing a carbamatetype $\mathrm{N}$-protecting group suitable for use in peptide synthesis) have been isolated in enantiomerically pure form by means of HPLC resolution (Scheme 16). This provides evidence that the chromatographic separation of enantiomers on chiral columns is nowadays a competitive alternative to other, more classical, resolution techniques.

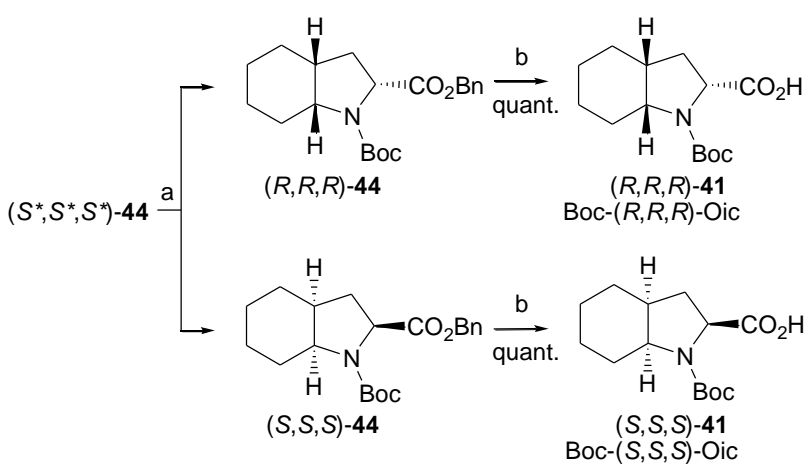

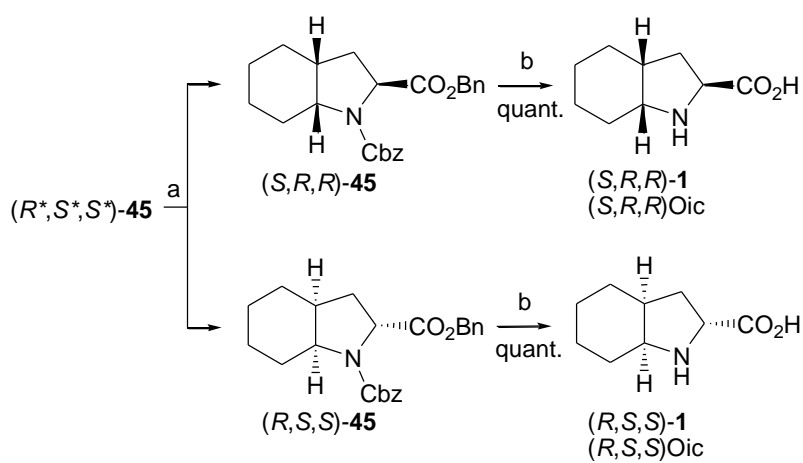

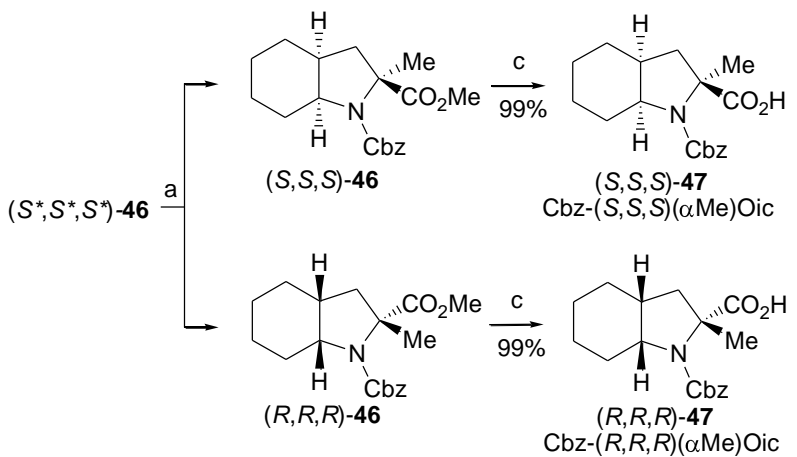

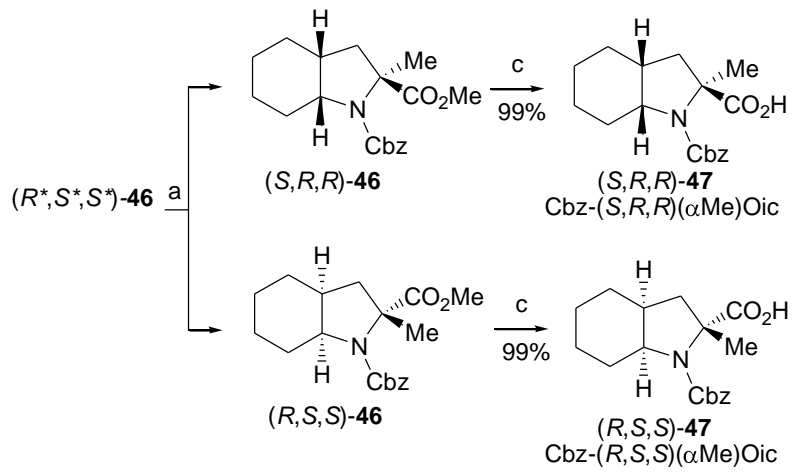

Scheme 16. Isolation of all cis-fused Oic and ( $\alpha \mathrm{Me})$ Oic stereoisomers in enantiomerically pure form after HPLC resolution. The target amino acids were isolated in the free form or as $N$-protected derivatives. The first eluted enantiomer is drawn at the upper position in all cases. Reagents and conditions: a) chiral HPLC; b) $\mathrm{H}_{2}, \mathrm{Pd} / \mathrm{C}$, EtOAc, r.t.; c) $1 \mathrm{~N} \mathrm{KOH}, \mathrm{MeOH}$, reflux. 


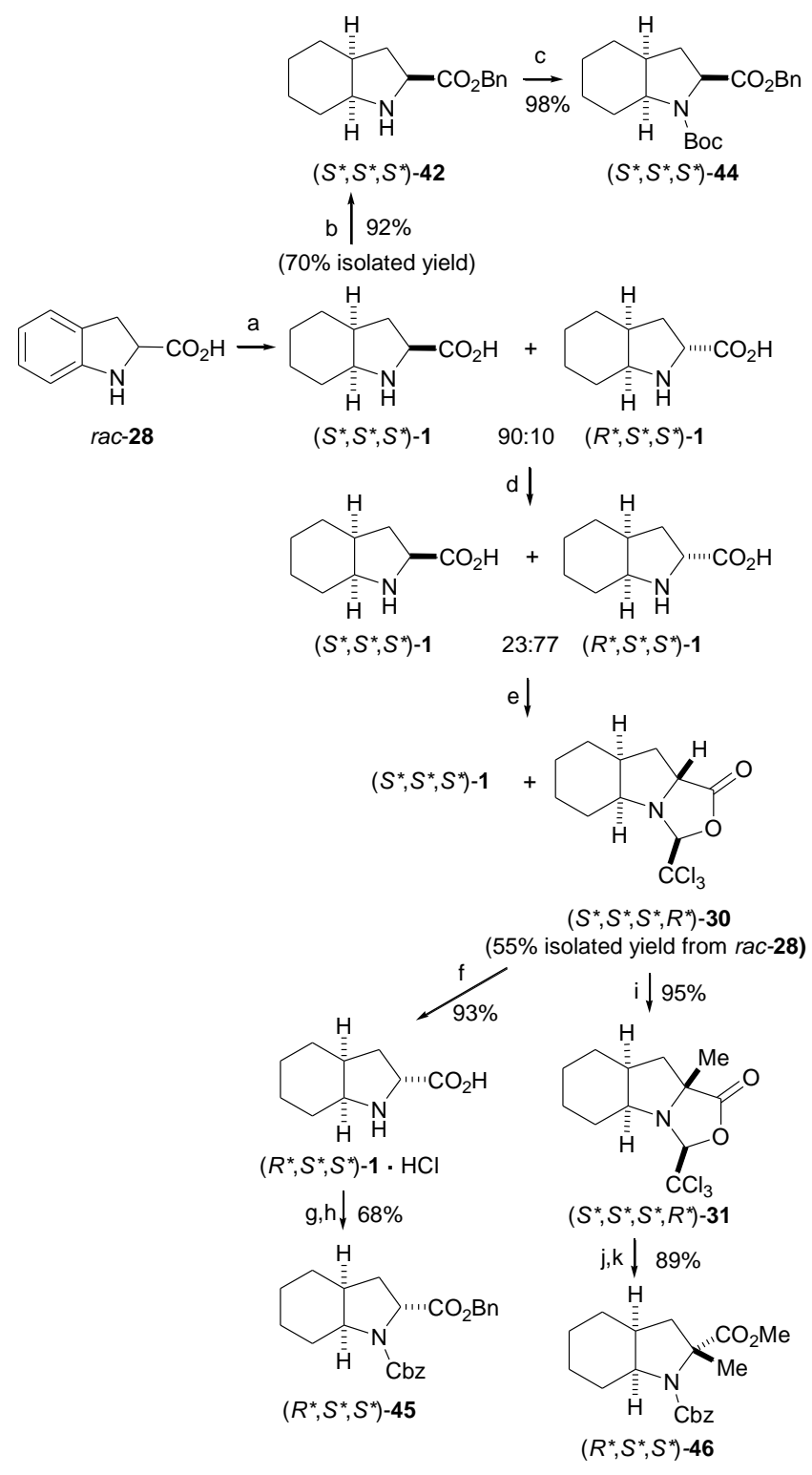

Scheme 17. Synthesis of racemic $\left(S^{*}, S^{*}, S^{*}\right)-\mathbf{4 4},\left(R^{*}, S^{*}, S^{*}\right)-\mathbf{4 5}$ and $\left(R^{*}, S^{*}, S^{*}\right)-46$ according to ref. 51,53. Reagents and conditions: a) $\mathrm{H}_{2}, \mathrm{PtO}_{2}$, $\mathrm{AcOH}, 60^{\circ} \mathrm{C}$ [recrystallization from EtOH affords pure $\left(S^{*}, S^{*}, S^{*}\right)-\mathbf{1}$ ]; b) $\mathrm{BnOH}$, TsOH, toluene, reflux; c) $\mathrm{Boc}_{2} \mathrm{O}, \mathrm{Me}_{4} \mathrm{~N}(\mathrm{OH})$, DMAP, THF, r.t.; d) salicylaldehyde, AcOH, reflux; e) $\mathrm{CCl}_{3} \mathrm{CHO}, \mathrm{CH}_{3} \mathrm{CN}$, r.t. [column chromatography of the mixture furnishes pure $\left.\left(S^{*}, S^{*}, S^{*}, R^{*}\right)-30\right]$; f) $3 \mathrm{~N}$ $\mathrm{HCl} / \mathrm{EtOAc}$, r.t.; g) 1. ClTMS, $\mathrm{CH}_{2} \mathrm{Cl}_{2}$; 2. $\mathrm{CbzCl}, i \mathrm{Pr}_{2} \mathrm{EtN}$, r.t.; h) $\mathrm{BnBr}$, $i \mathrm{Pr}_{2} \mathrm{EtN}, \mathrm{CH}_{2} \mathrm{Cl}_{2}$, r.t.; i) LDA, MeI, THF, -78 to $-50{ }^{\circ} \mathrm{C}$; j) 1 . MeONa, $\mathrm{MeOH}$, r.t.; 2. $\mathrm{CH}_{3} \mathrm{COCl}, \mathrm{MeOH}$, reflux; k) $\mathrm{CbzCl}, i \mathrm{Pr}_{2} \mathrm{EtN}, \mathrm{CH}_{2} \mathrm{Cl}_{2}$, r.t.
Prior to the HPLC resolution processes, synthetic routes for the multigram scale preparation of the racemic precursors $\left(S^{*}, S^{*}, S^{*}\right)$ $\mathbf{4 4},^{[51]}\left(R^{*}, S^{*}, S^{*}\right)-\mathbf{4 5},{ }^{[53]}\left(S^{*}, S^{*}, S^{*}\right)-\mathbf{4 6}^{[52]}$ and $\left(R^{*}, S^{*}, S^{*}\right)-\mathbf{4 6}^{[53]}$ were developed. They involved similar procedures to those described in Section 2.2, but employing racemic indoline-2carboxylic acid (rac-28) as the starting material.

Thus, the hydrogenation of rac-28 using platinum oxide as the catalyst, proceeded at atmospheric pressure and led to a 90:10 mixture of $\left(S^{*}, S^{*}, S^{*}\right)-\mathbf{1}$ and $\left(R^{*}, S^{*}, S^{*}\right)-\mathbf{1}$ (Scheme 17). ${ }^{[51]}$ The different solubility of these racemic compounds in comparison to that observed for the enantiopure counterparts (Scheme 6, iv) required the optimization of the recrystallization conditions, which finally provided pure $\left(S^{*}, S^{*}, S^{*}\right)$-1 in $70 \%$ yield (Scheme 17$)$. Next, the introduction of the orthogonal protecting groups was carried out by esterification of $\left(S^{*}, S^{*}, S^{*}\right)-\mathbf{1}$ with benzyl alcohol in the presence of $p$-toluenesulfonic acid and subsequent treatment of the ester obtained with di-tert-butyl dicarbonate. This provided $\left(S^{*}, S^{*}, S^{*}\right)-44$ in $63 \%$ overall yield from $r a c-28$.

The same 90:10 mixture of $\left(S^{*}, S^{*}, S^{*}\right)-\mathbf{1} /\left(R^{*}, S^{*}, S^{*}\right)-\mathbf{1}$ was used for the synthesis of $\left(R^{*}, S^{*}, S^{*}\right)-\mathbf{4 5}$ (Scheme 17). ${ }^{[53]}$ It was subjected to epimerization conditions analogous to those reported for the enantiomerically pure version (Scheme 8 ). When the 23:77 mixture of $\left(S^{*}, S^{*}, S^{*}\right)-\mathbf{1} /\left(R^{*}, S^{*}, S^{*}\right)-\mathbf{1}$ thus obtained was treated with trichloroacetaldehyde, only the $\left(R^{*}, S^{*}, S^{*}\right)-\mathbf{1}$ stereoisomer led to the corresponding tricyclic oxazolidinone $\left(S^{*}, S^{*}, S^{*}, R^{*}\right)-\mathbf{3 0}$, whereas $\left(S^{*}, S^{*}, S^{*}\right)-\mathbf{1}$ remained unreacted (Scheme 17). The oxazolidinone $\left(S^{*}, S^{*}, S^{*}, R^{*}\right)-\mathbf{3 0}$ was easily isolated from the reaction mixture and submitted to hydrolysis to afford pure $\left(R^{*}, S^{*}, S^{*}\right)$-1. Introduction of the $\mathrm{Cbz}$ group on the amino moiety followed by esterification with benzyl bromide afforded $\left(R^{*}, S^{*}, S^{*}\right)-\mathbf{4 5}$ in $35 \%$ global yield from $\mathrm{rac}-\mathbf{2 8}$

On the other hand, oxazolidinone $\left(S^{*}, S^{*}, S^{*}, R^{*}\right)-\mathbf{3 0}$ was subjected to an $\alpha$-methylation reaction that occurred with complete stereoselectivity and retention of configuration (Scheme 17) as earlier described for the enantiomerically pure version (Scheme 9). The resulting $\alpha$-methylated oxazolidinone was treated with sodium methoxide in methanol to afford an $N$-formylated amino ester, which was progressed to the methyl amino ester by heating under reflux in the presence of acetyl chloride. Next, the introduction of the $\mathrm{Cbz}$ group on the amino moiety was carried out by treatment with benzyl chloroformate. Following this route, $\left(R^{*}, S^{*}, S^{*}\right)-46$ was prepared from rac-28 in $47 \%$ overall yield. ${ }^{[53]}$ 


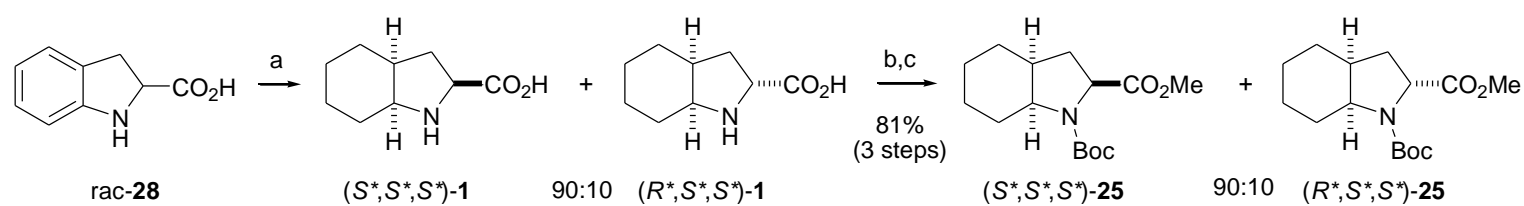

rac-28

$\left(S^{*}, S^{*}, S^{*}\right)-1 \quad 90: 10 \quad\left(R^{*}, S^{*}, S^{*}\right)-1$

$\left(S^{*}, S^{*}, S^{*}\right)-25$

d<smiles>COC(=O)c1cc2ccccc2n1C(=O)OC(C)(C)C</smiles>

48

49

$\left(S^{*}, S^{*}, S^{*}\right)-25$

$\left(S^{*}, S^{*}, S^{*}\right)-32$

89:11 $\left(R^{*}, S^{*}, S^{*}\right)-32$

$(75 \%$ isolated yield)

e,f $\downarrow 92 \%$

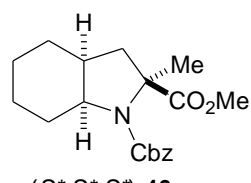

$\left(S^{*}, S^{*}, S^{*}\right)-46$

Scheme 18. Synthesis of racemic $\left(S^{*}, S^{*}, S^{*}\right)-46$ according to ref. 52. Reagents and conditions: a) $\mathrm{H}_{2}, \mathrm{PtO}_{2}, \mathrm{AcOH}^{\circ} 60{ }^{\circ} \mathrm{C}$; b) $\mathrm{SOCl}{ }_{2}$, $\mathrm{MeOH}$, r.t.; c) $\mathrm{Boc}_{2} \mathrm{O}$, $i \mathrm{Pr}_{2} \mathrm{EtN}$, DMAP, THF, r.t.; d) LDA, MeI, THF, -78 to $-50{ }^{\circ} \mathrm{C}$; e) $3 \mathrm{~N} \mathrm{HCl} / \mathrm{EtOAc}$, r.t.; f) $\mathrm{CbzCl}, i \mathrm{Pr}_{2} \mathrm{EtN}, \mathrm{CH}_{2} \mathrm{Cl}_{2}, \mathrm{r}_{\text {.t.; }}$ g) $1 . \mathrm{H}_{2} \mathrm{SO}_{4}, \mathrm{MeOH}$ reflux; 2 . Boc $2 \mathrm{O}$, DMAP, THF, r.t.; h) $\mathrm{H}_{2}$, $\mathrm{PtO}_{2}$, AcOH, r.t

Racemic $\left(S^{*}, S^{*}, S^{*}\right)-\mathbf{4 6}$ was prepared ${ }^{[52]}$ from $\left(S^{*}, S^{*}, S^{*}\right)-\mathbf{3 2}$ by replacement of the $N$-Boc protecting group by $\mathrm{Cbz}$ (Scheme 18). In turn, $\left(S^{*}, S^{*}, S^{*}\right)$-32 can be obtained by a similar route to that described for the enantiomerically pure compound (Scheme 10). Thus, transformation of the 90:10 mixture of racemic $\left(S^{*}, S^{*}, S^{*}\right)-\mathbf{1}$ and $\left(R^{*}, S^{*}, S^{*}\right)-\mathbf{1}$, obtained by hydrogenation of $\mathrm{rac}-\mathbf{2 8}$, into the corresponding $N$-Boc methyl ester derivatives followed by methylation at the $\alpha$-carbon afforded a 89:11 mixture of $\left(S^{*}, S^{*}, S^{*}\right)-32$ and $\left(R^{*}, S^{*}, S^{*}\right)-32$, from which the major compound can be isolated pure by column chromatography (Scheme 18).

Alternatively, the same $89: 11$ mixture of $\alpha$-methylated compounds, $\left(S^{*}, S^{*}, S^{*}\right)-32$ and $\left(R^{*}, S^{*}, S^{*}\right)-32$, may be obtained in a more straightforward manner starting from inexpensive indole-2carboxylic acid (48) (Scheme 18). ${ }^{[52]}$ The hydrogenation of its $N$ Boc protected methyl ester derivative (49) using platinum oxide as the catalyst proceeded under very mild conditions to give an excellent yield of $\left(S^{*}, S^{*}, S^{*}\right)-25$. Since the hydrogenation of the indole system entails the simultaneous incorporation of hydrogen to the three stereogenic centers of the molecule, it ensures the cis relative disposition of the two bridgehead hydrogen atoms and that at the $\alpha$ position. Accordingly, the hydrogenation of systems such as 49 means the most direct general procedure for the isolation of $\left(S^{*}, S^{*}, S^{*}\right)$ Oic derivatives provided that protecting groups resistant towards catalytic hydrogenation are present. $\alpha$-Methylation of pure $\left(S^{*}, S^{*}, S^{*}\right)$-25 provided the same 89:11 mixture of $\left(S^{*}, S^{*}, S^{*}\right)$ 32/( $\left.R^{*}, S^{*}, S^{*}\right)$-32 than that obtained from the 90:10 $\left(S^{*}, S^{*}, S^{*}\right)$ 25/( $\left.R^{*}, S^{*}, S^{*}\right)$-25 mixture (Scheme 18). Thus, $\left(S^{*}, S^{*}, S^{*}\right)-\mathbf{4 6}$ was obtained from 48 in excellent global yield $(61 \%)$. ${ }^{[52]}$

\section{Concluding remarks}

In this review, we have collected the methods available for the synthesis of the different stereoisomers of Oic and $(\alpha \mathrm{Me}) \mathrm{Oic}$ exhibiting a cis stereochemistry at the ring junction, in enantiomerically pure form. All the different cis-fused Oic and $(\alpha \mathrm{Me})$ Oic stereoisomers can be accessed in high optical purity through the adequate choice of a substrate-controlled stereoselective synthesis or by means of a racemic synthesis combined with a resolution procedure. Among the last, chromatographic resolutions prove especially robust to deliver multigram quantities of the different stereoisomers Oic and $(\alpha \mathrm{Me})$ Oic with high optical purity. All together, the different methods described facilitate the provision of a variety of Oic and $(\alpha \mathrm{Me})$ Oic stereoisomers, in enantiomerically pure form, that should encourage further investigations on their applications in peptide-based drug design and catalysis research.

\section{Abbreviations and acronyms}

Abbreviations and acronyms used in this article are summarized in Table 2.

Table 2.

\begin{tabular}{|c|c|}
\hline Ac & acetyl \\
\hline Alloc & allyloxycarbonyl \\
\hline aq. & aqueous \\
\hline $\mathrm{Bn}$ & benzyl \\
\hline Boc & tert-butoxycarbonyl \\
\hline $\mathrm{Bz}$ & benzoyl \\
\hline $\mathrm{Cbz}$ & benzyloxycarbonyl \\
\hline conc. & concentrated \\
\hline $\mathrm{Cy}$ & cyclohexyl \\
\hline DMAP & 4-dimethylaminopyridine \\
\hline DMF & $N, N$-dimethylformamide \\
\hline$e e$ & enantiomeric excess \\
\hline HMDS & hexamethyldisilazane \\
\hline LDA & lithium diisopropylamide \\
\hline$n \mathrm{Hx}$ & $n$-hexane \\
\hline Oic & octahydroindol-2-carboxylic acid \\
\hline Py & pyridine \\
\hline rac & racemic \\
\hline r.t. & room temperature \\
\hline TBDMSOTf & tert-butyldimethylsilyl trifluoromethanesulfonate \\
\hline THF & tetrahydrofuran \\
\hline TFA & trifluoroacetic acid \\
\hline Tf & trifluoromethanesulfonyl \\
\hline TMS & trimethylsilyl \\
\hline Ts & para-toluenesulfonyl \\
\hline
\end{tabular}




\section{Acknowledgements}

Financial support from the Ministerio de Ciencia e Innovación-FEDER (projects CTQ2007-62245 and CTQ2010-17436; predoctoral fellowship for P. L.) and Gobierno de Aragón (project PIP206/2005 and research group E40) is gratefully acknowledged.

[1] a) Peptides as Drugs. Discovery and Development (Ed.: B. Groner), Wiley-VCH, Weinheim, 2009; b) Peptides and Protein Design for Biopharmaceutical Applications (Ed.: K. J. Jensen), John Wiley \& Sons, Chichester, 2009

[2] A. K. Sato, M. Viswanathan, R. B. Kent, C. R. Wood, Curr. Opin. Biotech. 2006, 17, 638-642.

[3] a) P. Vlieghe, V. Lisowski, J. Martinez, M. Khrestchatisky, Drug Discov. Today 2010, 15, 40-56; b) C. L. Stevenson, Curr. Pharm. Biotech. 2009, 10, 122-137; c) C. Adessi, C. Soto, Curr. Med. Chem. 2002, 9, 963-978.

[4] a) B. K. Kay, M. P. Williamson, M. Sudol, FASEB J. 2000, 14, 231 241; b) G. Vanhoof, F. Goossens, I. de Meester, D. Hendriks, S Scharpé, FASEB J. 1995, 9, 736-744; c) M. W. MacArthur, J. M. Thornton, J. Mol. Biol. 1991, 218, 397-412.

[5] a) S. M. Cowell, Y. S. Lee, J. P. Cain, V. J. Hruby, Curr. Med. Chem. 2004, 11, 2785-2798; b) C. Toniolo, M. Crisma, F. Formaggio, C. Peggion, Biopolymers (Pept. Sci.) 2001, 60, 396-419; c) J. Venkatraman, S. C. Shankaramma, P. Balaram, Chem. Rev. 2001, 101, 3131-3152.

[6] a) J. M. Stewart, Peptides 2004, 25, 527-532; b) S. Reissmann, D. Imhof, Curr. Med. Chem. 2004, 11, 2823-2844; c) E. S. Monteagudo, F. Calvani, F. Catrambone, C. I. Fincham, A. Madami, S. Meini, R. Terracciano, J. Pept. Sci. 2001, 7, 270-283; d) M. Miskolzie, L. Gera, J. M. Stewart, G. Kotovych, J. Biomol. Struct. Dynam. 2000, 18, 249-260.

[7] a) J. M. Stewart, L. Gera, D. C. Chan, E. J. York, V. Simkeviciene, P. A. Bunn Jr., L. Taraseviciene-Stewart, Peptides 2005, 26, 12881291; b) D. Chan, L. Gera, J. Stewart, B. Helfrich, M. Verella-Garcia, G. Johnson, A. Baron, J. Yang, T. Puck, P. Bunn Jr., Proc. Natl. Acad. Sci. USA 2002, 99, 4608-4613; c) D. C. Chan, L. Gera, J. M Stewart, B. Helfrich, T. L. Zhao, W. Y. Feng, K. K. Chan, J. M. Covey, P. A. Bunn Jr., Clin. Cancer Res. 2002, 8, 1280-1287.

[8] a) E. A. Girnys, K. Sobczyk-Kojiro, H. I. Mosberg, Chem. Biol Drug Des. 2010, 75, 35-39; b) M. T. Nieman, F. Burke, M. Warnock, Y. Zhou, J. Sweigart, A. Chen, D. Ricketts, B. R. Lucchesi, Z. Chen, E. Di Cera, J. Hilfinger, J. S. Kim, H. I. Mosberg, A. H. Schmaier, J. Thromb. Haemost. 2008, 6, 837-845; c) F. M. Burke, M. Warnock, A. H. Schmaier, H. I. Mosberg, Chem. Biol. Drug Des. 2006, 68 235-238; d) M. T. Nieman, M. Warnock, A. A. K. Hasan, F. Mahdi, B. R. Lucchesi, N. J. Brown, L. J. Murphey, A. H. Schmaier, J. Pharmacol. Exp. Ther. 2004, 311, 492-501.

[9] R. P. Hicks, J. B. Bhonsle, D. Venugopal, B. W. Koser, A. J. Magill, J. Med. Chem. 2007, 50, 3026-3036.

[10] M. A. Bednarek, T. MacNeil, R. Tang, T. M. Fong, M. A. Cabello, M. Maroto, A. Teran, J. Med. Chem. 2007, 50, 2520-2526.

[11] a) K. Alfakih, A. S. Hall, Expert Opin. Pharmacother. 2006, 7, 63 71; b) M. Hurst, B. Jarvis, Drugs 2001, 61, 867-896; c) P. A. Todd A. Fitton, Drugs 1991, 42, 90-114.

[12] J. Lawandi, S. Gerber-Lemaire, L. Juillerat-Jeanneret, N. Moitessier, J. Med. Chem. 2010, 53, 3423-3438.

[13] B. Portevin, M. Lonchampt, E. Canet, G. De Nanteuil, J. Med. Chem. 1997, 40, 1906-1918.

[14] a) K. Ersmark, J. R. Del Valle, S. Hanessian, Angew. Chem. Int. Ed. 2008, 47, 1202-1223; b) S. Hanessian, L. Auzzas, Acc. Chem. Res. 2008, 41, 1241-1251; c) S. Hanessian, K. Ersmark, X. Wang, J. R. Del Valle, N. Blomberg, Y. Xue, O. Fjellström, Bioorg. Med. Chem. Lett. 2007, 17, 3480-3485.

[15] N. C. Barvian, C. J. C. Connolly, P. R. Guzzo, J. M. Hamby, J. L. Hicks, M. R. Johnson, V.-D. Le, L. H. Mitchell, W. H. Roark, PCT Int. Appl. WO 2004092132, 2004.

[16] a) R.-S. Luo, J. Weng, H.-B. Ai, G. Lu, A. S. C. Chan, Adv. Synth Catal. 2009, 351, 2449-2459; b) Y.-Y. Wu, Z. Chai, X.-Y. Liu, G.
Zhao, S.-W. Wang, Eur. J. Org. Chem. 2009, 904-911; c) B. Liégault, X. Tang, C. Bruneau, J.-L. Renaud, Eur. J. Org. Chem. 2008, 934-940; d) Y. H. Kim, Acc. Chem. Res. 2001, 34, 955-962; e) Y. H. Kim, S. H. Kim, D. H. Park, Tetrahedron Lett. 1993, 34, 6063-6066.

[17] For the sake of simplicity, a nomenclature without numerical locants will be used all over the text.

[18] a) R. J. Doll, B. Neustadt, M. E. Smith, C. V. Magatti, E. H. Gold PCT Int. Appl. WO 8701707, 1987; b) C. J. Blankley, J. S Kaltenbronn, D. E. DeJohn, A. Werner, L. R. Bennett, G. Bobowski, U. Krolls, D. R. Johnson, W. M. Pearlman, M. L. Hoefle, A. D. Essenburg, D. M. Cohen, H. R. Kaplan, J. Med. Chem. 1987, 30, 992-998; c) M. L. Hoefle, G. Bobowski, Eur. Pat. Appl. EP 0037231, 1981

[19] a) M. Vincent, J. Baliarda, B. Marchand, G. Remond, U.S. Patent 4,914,214, 1990; b) C. Pascard, J. Guilhem, M. Vincent, G. Rémond B. Portevin, M. Laubie, J. Med. Chem. 1991, 34, 663-669; c) M Vincent, B. Marchand, G. Rémond, S. Jaguelin-Guinamant, G. Damien, B. Portevin, J.-Y. Baumal, J.-P. Volland, J.-P. Bouchet, P. H. Lambert, B. Serkiz, W. Luitjen, M. Laubie, P. Schiavi, Drug Des Discovery 1992, 9, 11-28; d) R. N. Kankan, D. R. Rao, PCT Int. Appl. WO 2005100317, 2005; e) F. J. Sayago, M. I. Calaza, A. I. Jiménez, C. Cativiela, Tetrahedron 2008, 64, 84-91.

[20] a) M. Vincent, G. Rémond, B. Portevin, B. Serkiz, M. Laubie Tetrahedron Lett. 1982, 23, 1677-1680; b) C. Weiren, S. Jianxiang, L. Biao, Eur. Pat. Appl. EP 1792896, 2007.

[21] a) R. Kuwano, M. Kashiwabara, M. Ohsumi, H. Kusano, J. Am Chem. Soc. 2008, 130, 808-809; b) T. Dubuffet, P. Langlois, U.S Pat. Appl. US 0167273, 2006; c) A. Haider, S. Megevand, B. Nicollier, Y. Pannatier, Eur. Pat. Appl. EP 1864973, 2006.

[22] a) L. Belvisi, L. Colombo, M. Colombo, M. Di Giacomo, L. Manzoni, B. Vodopivec, C. Scolastico, Tetrahedron 2001, 57, 6463 6473; b) S. Hanessian, R. Margarita, A. Hall, S. Johnstone, M Tremblay, L. Parlanti, J. Am. Chem. Soc. 2002, 124, 13342-13343.

[23] R. Henning, H. Urbach, Tetrahedron Lett. 1983, 24, 5339-5342.

[24] T. Dubuffet, J.-P. Lecouve, Eur. Pat. Appl. EP 1354875, 2003.

[25] D. H. R. Barton, J. Guilhem, Y. Hervé, P. Potier, J. Thierry, Tetrahedron Lett. 1987, 28, 1413-1416.

[26] R. F. W. Jackson, N. Wishart, A. Wood, K. James, M. J. Wythes, J. Org. Chem. 1992, 57, 3397-3404

[27] J. P. Germanas, H. Wang, Synlett 1999, 33-36

[28] D. Seebach, M. Boes, R. Naef, W. B. Schweizer, J. Am. Chem. Soc 1983, 105, 5390-5398.

[29] F. J. Sayago, M. I. Calaza, A. I. Jiménez, C. Cativiela, Tetrahedron: Asymmetry 2008, 19, 2763-2766.

[30] F. J. Sayago, M. I. Calaza, A. I. Jiménez, C. Cativiela, Tetrahedron 2009, 65, 5174-5180

[31] a) D. Liu, G. Zhao, L. Xiang, Eur. J. Org. Chem. 2010, 3975-3984 b) S. Anas, H. B. Kagan, Tetrahedron: Asymmetry 2009, 20, 2193 2199

[32] W. G. Kim, J.-P. Kim, H. Koshino, K. Shin-Ya, H. Seto, I.-D. Yoo, Tetrahedron 1997, 53, 4309-4316.

[33] a) S. Lee, K. Y. Yi, S.-K. Kim, J. Suh, N. J. Kim, S. Yoo, B. H. Lee H. W. Seo, S.-O. Kim, H. Lim, Eur. J. Med. Chem. 2003, 38, 459471; b) N. Gruenfeld, J. L. Stanton, A. M. Yuan, F. H. Ebetino, L. J. Browne, C. Gude, C. F. Huebner, J. Med. Chem. 1983, 26, 1277 1282.

[34] S. Sato, H. Watanabe, M. Asami, Tetrahedron: Asymmetry 2000, 11, 4329-4340.

[35] a) J. L. Stanton, N. Gruenfeld, J. E. Babiarz, M. H. Ackerman, R. C. Friedmann, A. M. Yuan, W. Macchia, J. Med. Chem. 1983, 26 , 1267-1277; b) D. H. Kim, C. J. Guinosso, G. C. Buzby, Jr., D. R. Herbst, R. J. McCaully, T. C. Wicks, R. L. Wendt, J. Med. Chem. 1983, 26, 394-403.

[36] a) A. M. Maj, I. Suisse, C. Méliet, F. Agbossou-Niedercorn, Tetrahedron: Asymmetry 2010, 21, 2010-2014; b) N. Mrsic, T. Jerphagnon, A. J. Minnaard, B. L. Feringa, J. G. De Vries, 
Tetrahedron: Asymmetry 2010, 21, 7-10; c) R. Kuwano, M Kashiwabara, K. Sato, T. Ito, K. Kaneda, Y. Ito, Tetrahedron: Asymmetry 2006, 17, 521-535; d) R. Kuwano, K. Sato, T. Kurokawa, D. Karube, Y. Ito, J. Am. Chem. Soc. 2000, 122, 7614-7615.

[37] a) C. J. Vickers, T.-S. Mei, J.-Q. Yu, Org. Lett. 2010, 12, 2511 2513; b) R. Viswanathan, E. N. Prabhakaran, M. A. Plotkin, J. N Johnston, J. Am. Chem. Soc. 2003, 125, 163-168; c) S. Wagaw, R. A Rennels, S. L. Buchwald, J. Am. Chem. Soc. 1997, 119, 8451-8458.

[38] K. M. B. Gross, Y. M. Jun, P. Beak, J. Org. Chem. 1997, 62, 7679 7689.

[39] a) S. Alatorre-Santamaría, M. Rodríguez-Mata, V. Gotor-Fernández, M. C. de Mattos, F. J. Sayago, A. I. Jimenez, C. Cativiela, V. Gotor Tetrahedron: Asymmetry 2008, 19, 1714-1719; b) M. Kurokawa, T. Sugai, Bull. Chem. Soc. Jpn. 2004, 77, 1021-1025; c) G. M. R. Tombo, H.-P. Schär, O. Ghisalba, Agric. Biol. Chem. 1987, 51, 1833-1838.

[40] a) R. Geiger, V. Teetz, D. Langner, U.S. Patent 5,175,306, 1992; b) R. B. Potluri, H. Venkata Subramanian, A. R. C. Mulakala, H. P. Kodali, PCT Int. Appl. WO 2006137082, 2006.

[41] N. Hirata, U.S. Patent 7,439,036, 2008.

[42] Unpublished results.

[43] a) C. Cativiela, M. Ordóñez, Tetrahedron: Asymmetry 2009, 20, 163; b) C. Cativiela, M. D. Díaz-de-Villegas, Tetrahedron: Asymmetry 2007, 18, 569-623; c) C. Cativiela, M. D. Díaz-deVillegas, Tetrahedron: Asymmetry 2000, 11, 645-732; d) C. Cativiela, M. D. Díaz-de-Villegas, Tetrahedron: Asymmetry 1998, 9 , 3517-3599.

[44] a) Chiral Separation Methods for Pharmaceutical and Biotechnological Products (Ed.: S. Ahuja), John Wiley \& Sons, Hoboken (USA), 2011; b) Preparative Enantioselective Chromatography (Ed.: G. B. Cox), Blackwell, Oxford (UK), 2005.

[45] a) S. Royo, A. I. Jiménez, C. Cativiela, Tetrahedron: Asymmetry 2006, 17, 2393-2400; b) M. Lasa, P. López, C. Cativiela, Tetrahedron: Asymmetry 2005, 16, 4022-4033; c) A. I. Jiménez, P. López, C. Cativiela, Chirality 2005, 17, 22-29; d) C. Cativiela, M Lasa, P. López, Tetrahedron: Asymmetry 2005, 16, 2613-2623; e) A M. Gil, E. Buñuel, P. López, C. Cativiela, Tetrahedron: Asymmetry 2004, 15, 811-819; f) C. Cativiela, P. López, M. Lasa, Eur. J. Org. Chem. 2004, 3898-3908; g) M. Alías, M. P. López, C. Cativiela, Tetrahedron 2004, 60, 885-891; h) S. Royo, P. López, A. I. Jiménez, L. Oliveros, C. Cativiela, Chirality 2002, 14, 39-46; i) M. Alías, C. Cativiela, A. I. Jiménez, P. López, L. Oliveros, M. Marraud, Chirality 2001, 13, 48-55; j) A. I. Jiménez, P. López, L. Oliveros, C. Cativiela, Tetrahedron 2001, 57, 6019-6026; k) C. Cativiela, M. D. Díaz-de-Villegas, A. I. Jiménez, P. López, M. Marraud, L. Oliveros, Chirality 1999, 11, 583-590.

[46] Chiralpak ${ }^{\circledR}$ IA contains 3,5-dimethylphenylcarbamate of amylose as the chiral selector: T. Zhang, C. Kientzy, P. Franco, A. Ohnishi, Y. Kagamihara, H. Kurosawa, J. Chromatogr. A 2005, 1075, 65-75.

[47] Chiralpak $^{\circledR}$ IB is based on 3,5-dimethylphenylcarbamate of cellulose: T. Zhang, D. Nguyen, P. Franco, T. Murakami, A. Ohnishi, H Kurosawa, Anal. Chim. Acta 2006, 557, 221-228.

[48] Chiralpak ${ }^{\circledR}$ IC contains 3,5-dichlorophenylcarbamate of cellulose: T. Zhang, D. Nguyen, P. Franco, Y. Isobe, T. Michishita, T. Murakami, J. Pharm. Biomed. Anal. 2008, 46, 882-891.

[49] a) Y. Okamoto, T. Ikai, Chem. Soc. Rev. 2008, 37, 2593-2608; b) P. Franco, T. Zhang, J. Chromatogr. B 2008, 875, 48-56; c) T. Ikai, C. Yamamoto, M. Kamigaito, Y. Okamoto, Polym. J. 2006, 38, 91-108 d) C. Yamamoto, Y. Okamoto, Bull. Chem. Soc. Jpn. 2004, 77, $227-$ 257; e) E. Yashima, J. Chromatogr. A 2001, 906, 105-125; f) Y. Okamoto, E. Yashima, Angew. Chem., Int. Ed. 1998, 37, 1020-1043.

[50] T. Zhang, P. Franco, Analytical and Preparative Potential of Immobilized Polysaccharide-Derived Chiral Stationary Phases, in Chiral Separation Techniques (Ed.: G. Subramanian), Wiley-VCH Weinheim (Germany), 2007, pp. 99-134.

[51] Resolution of $\left(S^{*}, S^{*}, S^{*}\right)-44$ : F. J. Sayago, A. I. Jiménez, C. Cativiela, Tetrahedron: Asymmetry 2007, 18, 2358-2364.

[52] Resolution of $\left(S^{*}, S^{*}, S^{*}\right)-46:$ F. J. Sayago, M. J. Pueyo, M. I. Calaza, A. I. Jiménez, C. Cativiela, submitted.
[53] Resolution of $\left(R^{*}, S^{*}, S^{*}\right)-\mathbf{4 5}$ and $\left(R^{*}, S^{*}, S^{*}\right)-\mathbf{4 6}$ : unpublished results. 
